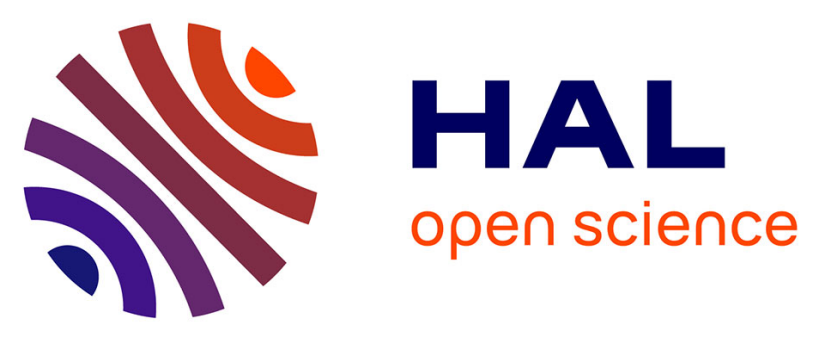

\title{
Thermal plasticity and sensitivity to insecticides in populations of an invasive beetle: Cyfluthrin increases vulnerability to extreme temperature
}

Julie Engell Dahl, Sapho-Lou Marti, Hervé Colinet, Claudia Wiegand, Martin Holmstrup, David Renault

\section{To cite this version:}

Julie Engell Dahl, Sapho-Lou Marti, Hervé Colinet, Claudia Wiegand, Martin Holmstrup, et al.. Thermal plasticity and sensitivity to insecticides in populations of an invasive beetle: Cyfluthrin increases vulnerability to extreme temperature. Chemosphere, 2021, 274, pp.129905. 10.1016/j.chemosphere.2021.129905 . hal-03155982

\section{HAL Id: hal-03155982}

https://hal-univ-rennes1.archives-ouvertes.fr/hal-03155982

Submitted on 8 Mar 2021

HAL is a multi-disciplinary open access archive for the deposit and dissemination of scientific research documents, whether they are published or not. The documents may come from teaching and research institutions in France or abroad, or from public or private research centers.
L'archive ouverte pluridisciplinaire HAL, est destinée au dépôt et à la diffusion de documents scientifiques de niveau recherche, publiés ou non, émanant des établissements d'enseignement et de recherche français ou étrangers, des laboratoires publics ou privés. 
Title:

Thermal plasticity and sensitivity to insecticides in populations of an invasive beetle: Cyfluthrin increases vulnerability to extreme temperature

Julie ENGELL DAHL ${ }_{1}$, Sapho-Lou MARTI 1 , Hervé COLINET 1 , Claudia WIEGAND 1 , Martin HOLMSTRUP 2 and David RENAULT 1,3

${ }_{1}$ Univ Rennes, CNRS, ECOBIO [(Ecosystèmes, biodiversité, évolution)] - UMR 6553, F-35000 Rennes, France

${ }_{2}$ University of Aarhus, Department of Bioscience, Section for Terrestrial Ecology, Vejlsøvej 25, 8600 Silkeborg, Denmark

${ }_{3}$ Institut Universitaire de France, 1 rue Descartes, Paris, France

Corresponding author:

Julie Engell Dahl

Tlf:

$+4522447443$

Address:

Univ Rennes, CNRS, ECOBIO [(Ecosystèmes, biodiversité, évolution)]

UMR 6553, F-35000 Rennes

France

E-mail:

julie.bjorge@univ-rennes1.fr 
J.E.D. and D.R. designed the experiments, carried out by J.E.D. and S. L. M.. D.R. and M.H. supervised the project. J.E.D. and D.R. derived the models and J.E.D. and S.L.M. analysed the data. H.C. and D.R. assisted with data analysis. J.E.D. and D.R. wrote the manuscript in consultation with all authors. All authors discussed the results and contributed to the final manuscript. 


\begin{abstract}
Climate change increases average temperatures and the occurrence of extreme weather events, in turn accentuating the risk of organism exposure to temperature stress. When thermal conditions become stressful, the sensitivity of insects toward insecticides can be exacerbated. Likewise, exposure of insects to insecticides can subsequently influence their ability to handle stressful temperatures. Here, we investigated the effects of constant temperature and daily heat spikes, in presence/absence of insecticide treatment (cyfluthrin), on the condition (impairment of mobility) and thermal tolerance to cold $\left(-6^{\circ} \mathrm{C}\right)$ and heat $\left(42.5^{\circ} \mathrm{C}\right)$ of the terrestrial beetle Alphitobius diaperinus. The responses of insects from four populations (three farm-collected populations, one laboratory population) to different durations of extreme temperature exposure were compared. The results showed that the laboratory population was generally more sensitive to extreme cold and heat temperatures, with less than $50 \%$ of adults recovering after an exposure at -6 or $+42.5^{\circ} \mathrm{C}$ for $3 \mathrm{~h}$. Significant differences in the level of thermal tolerance were also found among insects from poultry farms. Cyfluthrin exposure incurred detrimental effects to insects' condition in all but one population. For two out of the four populations, mobility impairment was increased when adults were exposed to daily heat spikes (6 hours per day at $38{ }^{\circ} \mathrm{C}$ ) and cyfluthrin simultaneously, compared to cyfluthrin exposure at constant temperatures; yet, no significant interaction between the two stressors was found. Finally, using one farm collected population, effects of pre-exposure to cyfluthrin on extreme temperature tolerance provided another example of the toxicant-induced climate sensitivity in insects.
\end{abstract}


2 Thermal plasticity and sensitivity to insecticides in populations of an invasive beetle:

\section{Cyfluthrin increases vulnerability to extreme temperature}

4

5 Julie ENGELL DAHL ${ }^{1}$, Sapho-Lou MARTI ${ }^{1}$, Hervé COLINET ${ }^{1}$, Claudia WIEGAND ${ }^{1}$, Martin HOLMSTRUP ${ }^{2}$

6 and David RENAULT ${ }^{1,3}$

7 ' Univ Rennes, CNRS, ECOBIO [(Ecosystèmes, biodiversité, évolution)] - UMR 6553, F-35000 Rennes,

8 France

9 '2University of Aarhus, Department of Bioscience, Section for Terrestrial Ecology, Vejlsøvej 25, 8600

10 Silkeborg, Denmark

$11{ }^{3}$ Institut Universitaire de France, 1 rue Descartes, Paris, France

12

13

Keywords:

14 Pesticide, thermal variation, tolerance, heat spike, pyrethroid, insect

15 


\section{Introduction}

Over the course of their life, all living organisms, including insects, are confronted with a range of environmental conditions which vary spatially and temporally (Hirose and Nakamura 2005; Mann, Bradley, and Hughes 1998; Soranno et al. 2019). In some instances, environmental constraints may be exacerbated by the currently changing climatic conditions. This increases the occurrence of extreme weather events and the probability of organisms' exposure to higher temperatures (Hansen, Sato, and Ruedy 2012; IPCC 2014; Stillman 2019), heightening the risk of organism exposure to heat stress. In turn, several life history traits of individual insects can be affected (Bozinovic et al. 2011; Kingsolver, Diamond, and Buckley 2013; Renault 2011), with cascading effects on population demography and organism evolution (Chown et al. 2010; Colinet et al. 2015; Katz and Brown 1992; Moe et al. 2013). When temperature varies, heat spikes are more likely to occur, and they are expected to have greater evolutionary significance - and pose greater threat to species performance - than increase in average temperature (Katz and Brown 1992; Vasseur et al. 2014). Yet, whatever the nature of the physiological and biochemical mechanisms triggered by thermal stress, their activation may weaken the ability of organisms to deal with other environmental constraints, or conversely magnify these abilities when the responses elicit cross tolerance phenomena (Chen and Stillman 2012; Noyes and Lema 2015; Sinclair et al. 2013). In this context, investigating insects' ability to cope with stress under and after exposure to varying temperature regimes provides useful information about their sensitivity to environmental stress, and for future insights into their geographic distribution (Bozinovic and Pörtner 2015; Buckley et al. 2010; Ma, Hoffmann, and Ma 2015).

Besides climatic conditions, adverse environmental effects on insects are also caused by the unintentional spread of man-made contaminants, in particular by the use of various pesticides in agriculture and horticulture (Aviles et al. 2019; Calow 1991; Köhler and Triebskorn 2013). The use of pesticides has become widespread in many regions of the world where agricultural intensity has increased (Tilman et al. 2002), representing a threat to biodiversity in general. While valuable insights of the effects of insecticides on behaviour (Dewer et al. 2016), olfaction (Lalouette et al. 2016), reproduction and development (Abbes et al. 2015) have been gathered, these investigations were commonly conducted by exposing the organisms to constant and optimal temperatures, as prescribed in standardized tests (Camp and Buchwalter 2016; Khan and Akram 2014). Yet, the 
inclusion of daily thermal fluctuations is needed to better simulate the conditions experienced by free-ranging organisms in natural and anthropogenic environments, and thus increase the quality and realism of the outcomes of these investigations (Colinet et al. 2015; Verheyen and Stoks 2019). Moreover, thermal tolerance can vary significantly among insect populations originating from different environments (Engell Dahl et al. 2019; Käfer et al. 2020), as is also the case for pesticide exposure (see Hawkins et al. (2019) for a review of the different mechanisms that may confer different level of insecticide resistance among insect populations). When assessing the effects of environmental stressors on insects' ecology, it has thus become crucial to consider multiple populations (of different exposure or adaptation history) in the experimental designs to get a larger coverage of the range of responses that could be expected at the species level.

The possible combined effects of climate change and environmental pollution on organisms, and wildlife in general, have been reviewed by Noyes and Lema (2015). These authors reported that chemical exposure may affect organisms' sensitivity to climate change by disrupting physiological responses to diurnal and seasonal thermal fluctuations. In particular, the alteration of endocrine system functioning and energy balance in toxicant-exposed organisms may subsequently alter their thermal performance curves, potentially challenging their ability to survive thermal stress. In several instances, it has been suggested that the simultaneous exposure to pollutants, including endocrine disrupting chemicals, and climate change could result in synergistic actions (Cairns, Heath, and Parker 1975; Hooper et al. 2013; Laskowski et al. 2010; Moe et al. 2013). When sequential exposures occur, climatic stress can influence sensitivity towards pollutants, and the reverse is also true, e.g. previous exposure to a pollutant can influence the tolerance to climatic stress (Hooper et al. 2013).

Nowadays, studies assessing the impacts of multiple stressors, including temperature, are increasingly needed (Kaunisto, Ferguson, and Sinclair 2016; Orr et al. 2020), as such investigations greatly improve our estimates of the effects of interactions among environmental stressors on insects. Holmstrup et al. (2010) reviewed the available studies that assessed the combined effects of pesticide and temperature exposures, and reported only few works that considered daily thermal fluctuations, or daily heat spikes, in their experimental designs. Since this review has been published, the number of studies that combined temperature and toxicant exposures has started to accumulate, reporting how thermal conditions could modify the effects of pesticides on insects (Op 
de Beeck, Verheyen, and Stoks 2018; Camp and Buchwalter 2016; Delnat et al. 2019; Harwood, You, and Lydy 2009; Verheyen, Delnat, and Stoks 2019; Verheyen and Stoks 2019; Willming, Qin, and Maul 2013). For example, Verheyen and Stoks (2019) found that exposure of damselfly larvae to the organophosphate chlorpyrifos did not affect the survival of individuals maintained at constant $20^{\circ} \mathrm{C}$. Conversely, the mortality of the larvae was increased under daily thermal fluctuations of 5 (17.5$\left.22.5^{\circ} \mathrm{C}\right)$ or $10^{\circ} \mathrm{C}\left(15-25^{\circ} \mathrm{C}\right)$. Delnat et al. (2019) reported that daily thermal fluctuations of 7 (16.5$\left.23.5^{\circ} \mathrm{C}\right)$ or $14{ }^{\circ} \mathrm{C}\left(13-27^{\circ} \mathrm{C}\right)$ slightly increased the mortality of the larvae of the mosquito Culex pipiens exposed to chlorpyrifos, while having no effect on adults. Working with heat waves (constant heat exposure of damselfly larvae over three consecutive days), Arambourou and Stoks (2015) reported that the subsequent exposure to chlorpyrifos did not change mortality rates of the larvae. However, the higher inhibition of acetylcholine esterase suggested that heat waves may increase the sensitivity of damselflies to this chemical. More recent studies have examined the effects of successive heat spikes and pesticide exposure (Meng, Delnat, and Stoks 2020), and the delayed effects of pesticide exposures on life histories of insects (Dinh, Janssens, and Stoks 2016).

Even though Delnat, Janssens, and Stoks (2019) found the effect of warming on pesticide toxicity to be dependent on other factors of their experimental setup, results from the available literature generally underline the importance of incorporating more realism into the experimental designs when investigating the interaction between pesticide and temperature (Böttger, Schaller, and Mohr 2012). Moreover, all but one of these studies used insect larvae, and all investigations were based on aquatic species, meaning that terrestrial insect species and adult life stages are severely underrepresented from this research. Likewise, some studies have investigated the thermal tolerance of insects after they were exposed to pesticides (Op de Beeck, Verheyen, and Stoks 2017, 2018; Delnat et al. 2019; Meng, Delnat, and Stoks 2020). Yet again, all of these investigations have focused on aquatic larvae, and used the organophosphate chlorpyrifos. Other chemicals, including pyrethroids, which are also highly toxic to insects (Tang et al. 2017), should be considered. Finally, no study examined the effects of sequential exposure to daily thermal fluctuations and pesticide on the subsequent thermal tolerance in terrestrial insects.

In order to contribute to the abovementioned research gaps concerning the interaction of climate and pollutant stress, we aimed at investigating the effects of daily heat spikes and insecticide treatment on the thermal tolerance of adults of the lesser mealworm Alphitobius diaperinus 
106

107

108

109

(Panzer) (Coleoptera: Tenebrionidae), as well as comparing the performance of populations of $A$. diaperinus of different exposure histories to temperature and insecticide. This insect pest, pullulating in poultry farms from many regions worldwide (Geden and Hogsette 1994; Johnson, Gbon, and Boga 2018; Rueda and Axtell 1997), represents a fitting model for research combining ecophysiological and ecotoxicological investigations. Insects can be collected in large numbers from geographically distant and unconnected habitats (poultry farms), making it possible to work with different and locally adapted strains. In these anthropogenic environments, the lesser mealworms are exposed to fluctuating temperatures, as broilers optimize poultry production by running a standardized cycle (which has to be closely followed to maintain profitability (Donald 2010)) of weekly decreasing temperatures, i.e. starting from $\approx 31$ and reaching $\approx 17^{\circ} \mathrm{C}$ over approximately seven weeks (Salin, Delettre, and Vernon 2003). This provides an excellent habitat for lesser mealworms, that have been found to grow well, i.e. with a very high energy conversion efficiency at 23 to $31{ }^{\circ} \mathrm{C}$ (Bjørge et al. 2018). Temperature extremes up to $48{ }^{\circ} \mathrm{C}$ have also been measured in the litter where A. diaperinus thrive (Salin and Vernon 1997), meaning that the insect can be exposed to heat spikes. The poultry houses are disinfected from time to time with chemicals, including the structural type II pyrethroid, cyfluthrin (the use of this insecticide will be banned in France from July $21^{\text {st }}, 2021$ (ANSES 2020)). This insecticide is an inhibitor of insect nerve cell sodium channels, leaving them open and causing paralysis, tremors, and eventually death (Lushchak et al. 2018). It is sprayed at the end of each broiler flock for controlling outbreaks of $A$. diaperinus, and during the disinfection and cleaning of the poultry farm, the heating system is stopped, doors of the building are left opened, and temperature can vary from $-5^{\circ} \mathrm{C}$ to $31^{\circ} \mathrm{C}$ (Salin, Delettre, and Vernon 2003).

As a first part of the study, we compared the basal thermal tolerance of $A$. diaperinus from four populations, by measuring their ability to recover from exposure to extreme cold or heat temperatures for different durations. We hypothesized that the beetles' recovery from thermal stress would be faster in populations that experienced temperature fluctuations in their original environment, as previously reported on several other insect models (Arias, Poupin, and Lardies 2011; Bozinovic et al. 2011; Cavieres et al. 2019). As a second part of the study, we were interested in comparing the effects of exposure to an environmentally relevant dose of the insecticide cyfluthrin on the condition of insects maintained at constant temperatures or subjected to daily heat spikes. We hypothesized that populations which had experienced frequent pesticide exposure 
would perform better than laboratory-reared adults (Hamm et al. 2006; Lambkin and Rice 2009). Finally, the population with the highest pesticide tolerance was exposed to different temperature regimes, without pesticide exposure or with different concentrations of cyfluthrin (up to those recommended by commercial formulations). Subsequently, the recovery times of individuals from the different treatments after an exposure to temperature extremes were assessed. Insects preexposed to daily heat spikes were expected to recover faster from heat shock, but slower from cold shock treatments, compared to insects kept at constant temperature. Furthermore, insects exposed to insecticides were hypothesized to be characterized by a lower ability to cope with temperature stress, either due to an increased toxicity of the chemical with daily heat spikes or decreased ability to cope with heat shock after chemical stress (Op de Beeck, Verheyen, and Stoks 2017; Delnat et al. 2019; Meng, Delnat, and Stoks 2020).

\section{Materials and methods}

\subsection{Rearing of the insects}

Adults of $A$. diaperinus were collected from three poultry farms in Brittany, France, thereafter referred to as FARM1 (sampled at Miniac-sous-Bécherel, 48 $17^{\circ} 10^{\prime \prime} \mathrm{N}, 1^{\circ} 55^{\prime} 51^{\prime \prime} \mathrm{W}$ ), FARM2 (sampled at Plaine Haute, $48^{\circ} 26^{\prime} 44^{\prime \prime} \mathrm{N}, 2^{\circ} 51^{\prime} 16^{\prime \prime} \mathrm{W}$ ), and FARM3 (sampled at Pommerit-le-Vicomte, $\left.48^{\circ} 37^{\prime} 10^{\prime \prime} \mathrm{N}, 3^{\circ} 05^{\prime} 15^{\prime \prime} \mathrm{W}\right)$. In addition, larvae of $A$. diaperinus were obtained from Proti-Farm via a pet shop (Envies Animales, Saint-Jacques-de-la-Lande, Brittany, France). Insects from this latter population, hereafter referred to as $L A B$, were reared over many generations under controlled conditions $\left(25{ }^{\circ} \mathrm{C}\right.$, relative humidity $50 \%$, no light) in a supposedly pollutant free environment. Because LAB insects are produced and used as a dietary food supply for pets (e.g. lizards), they are in very good physiological condition (Bjørge et al. 2018).

All adults were kept at $25^{\circ} \mathrm{C}$, in darkness, in plastic containers with sawdust for minimum 4 weeks prior to experimental start. They were supplied with water and food ad libitum, in the form of water in microtubes with cotton and dry dog food pellets. This procedure allowed standardisation of the temperature, humidity, and trophic conditions experienced by the adults before the assays. The LAB larvae were additionally provided with a block of polystyrene to burrow in for pupation, and oat bran for the first four weeks to further encourage their development into adults (Rice and Lambkin 2009). The sex and age of the adults was not considered in our experiments. 


\subsection{Experimental design}

\subsubsection{Characterization of the thermal tolerance of the insects from different populations}

In order to compare the thermal tolerance of the insects from the four populations, adults were exposed to two extreme temperatures, -6 or $+42.5^{\circ} \mathrm{C}$, in a cryothermostat (VWR Collection, AP15R30). This procedure is derived from protocols commonly used for assessing the thermal tolerance in insects (Hazell et al. 2008; Sinclair, Coello Alvarado, and Ferguson 2015). At -6 and $+42.5^{\circ} \mathrm{C}$, the lesser mealworms are expected to fall into coma (see Supplementary File $\mathbf{1}$ for the results of the preliminary tests that allowed us designing the methodology). Each insect was exposed to one of these two extreme temperatures for one of six durations: $15 \mathrm{~min}, 30 \mathrm{~min}, 1 \mathrm{~h}, 2 \mathrm{~h}, 3 \mathrm{~h}$ or $4 \mathrm{~h}$, in darkness. This range of stress durations allowed us to describe and compare thermal tolerance among populations. At least four replicates of 10 adults (test tube with rubber cap) were used for each exposure duration and temperature combination. At the end of the thermal treatment ( -6 or $+42.5^{\circ} \mathrm{C}$ ), each group of 10 insects was directly transferred into Petri dishes and observed for up to 40 seconds every 5 minutes over $2 \mathrm{~h}$ at room temperature $\left(19 \pm 1^{\circ} \mathrm{C}\right.$ ) (Supplementary File 2). During each observation period, the recovery of the insects was scored by registering the individuals as either "Active" or "Impaired/immobile"; insects were characterized as "Active" when they exhibited coordinated movements of all limbs when stimulated, all other states were registered as "Impaired/immobile". The temperatures, both in the cryothermostat and in the room where recovery observations took place, were monitored using iButtons ${ }^{\circledast}$ (iButtonLink, LLC., Whitewater, USA).

\subsubsection{Effect of daily heat spikes and cyfluthrin exposure}

Here, we combined two abiotic stresses by jointly exposing adult $A$. diaperinus to both moderately stressful heat spikes and insecticide for eight days, before assessing any visible impairment or death of exposed individuals. One temperature cabinet was set to constant $26^{\circ} \mathrm{C}$ (control temperature), and another cabinet varied the temperature by holding a $6 \mathrm{~h}$ period at $38^{\circ} \mathrm{C}$, followed by $18 \mathrm{~h}$ at 26 ${ }^{\circ} \mathrm{C}$ (Supplementary File 2); the two cabinets were MIR 154 Panasonic programmable incubators. The experiment was run in dark conditions.

Insects were placed in glass Petri dishes (10 cm diameter) with a fitting filter paper covering the bottom. For insecticide application, cyfluthrin (pure molecule standard, CAS-number 68359-37-5, 
Sigma-Aldrich) was dissolved in acetone, and a volume of $2 \mathrm{~mL}$ of appropriately diluted solution was transferred to the filter paper. Pre-testing the insects' susceptibility to cyfluthrin led to preparation of two distinct insecticide concentrations, so that the applied dose was $20 \mathrm{mg}$ cyfluthrin $/ \mathrm{m}^{2}$ for populations FARM1, 2 and 3 , and $0.5 \mathrm{mg}$ cyfluthrin $/ \mathrm{m}^{2}$ for $\mathrm{LAB}$. We had to reduce the cyfluthrin dose significantly for the $L A B$ population, as the $20 \mathrm{mg}$ cyfluthrin $/ \mathrm{m}^{2}$ concentration killed all adults within a day at our experimental temperatures. These cyfluthrin concentrations induced negligible knockdown $(<5 \%)$ over prolonged exposures in the works of Desvignes-Labarthe (2018) and Renault and Colinet (Submitted). These concentrations also range in the values that may be encountered by the insects in poultry houses (Salin, Delettre, and Vernon 2003). In the other Petri dishes, $2 \mathrm{~mL}$ of pure acetone was added to control for any effect of the solvent. All Petri dishes were left to dry under a fume hood for at least 10 min before the tests, which effectively evaporated all acetone. The exiting literature reveals that cyfluthrin remains efficient over seven days (Guillebeau, All, and Javid 1989), with knockdown effects remaining unchanged when the beetle Tribolium castaneaum were assessed eight weeks after the chemical was applied (Arthur 1999) Finally, starting from an initial concentration of $17.3 \mathrm{mg} / \mathrm{m}^{2}$, (Nakagawa et al. 2017) reported that cyfluthrin concentration decreased by ca. $17 \%$ after 56 days. Thus, even if changes in cyfluthrin concentration were not monitored here, it is assumed that it remained close to the nominal concentration.

For all treatments, the insects were supplied with a water source $(0.5 \mathrm{~mL}$ microtube containing water and cotton) and a food source (approx. $0.8 \mathrm{~g}$ dog food pellet). For each population, a set of Petri dishes treated with the insecticide and a set of dishes without pesticide treatment were placed in the temperature cabinets ( 8 to 30 dishes of each, as specified in Table 1) along with an iButton ${ }^{\circledR}$ (iButtonLink, LLC., Whitewater, USA) measuring both temperature and humidity. Each Petri dish in experiments with poultry house collected populations contained 30 individuals, and for the LAB population, each Petri dish contained 20 individuals, due to limited number of individuals (Table 1). Previous experiments that examined the sensitivity of $A$. diaperinus to insecticides (including cyfluthrin) revealed that densities from 10 to 30 adults per Petri dish had no effects on the results (Desvignes-Labarthe 2018; Renault and Colinet Submitted). 
Table 1 Overview of number of dishes and number of individuals per dish used for assessing the effects of temperature regime (constant temperature or daily heat spikes), with and without the insecticide cyfluthrin, on the locomotory capacities of adult Alphitobius diaperinus.

\begin{tabular}{|c|c|c|c|c|}
\hline Treatment & \multicolumn{2}{|c|}{ Without insecticide } & \multicolumn{2}{c|}{ Insecticide-exposed } \\
\hline Population & Dishes (N) & $\frac{\text { Animals (N) }}{30}$ & $\frac{\text { Dishes (N) }}{20}$ & $\frac{\text { Animals (N) }}{30}$ \\
FARM1 & 20 & 30 & 30 & 30 \\
FARM2 & 21 & 30 & 10 & 30 \\
FARM3 & 10 & 20 & 12 & 20 \\
LAB & 8 & & 12 & \\
\hline
\end{tabular}

After eight days, and 17 hours after the last peak of heat, the state of each individual was noted: the insects were considered as either "Active" (no apparent effect of the treatment on the locomotory activities of the insects), "Impaired" (locomotor deficits: difficulties in moving limbs, or laying on their backs while moving) or "Immobile" (no observable movement).

\subsubsection{Effect of daily heat spikes and cyfluthrin exposure on recovery from exposure to extreme}

\section{temperatures}

In the third part of the study, we measured the capabilities of adult $A$. diaperinus to recover from cold or heat shocks after they had been exposed to insecticide and/or daily heat spikes for eight days. As a non-negligible part of the adults from LAB, FARM2 and FARM3 were impaired or immobile after they were exposed to cyfluthrin concentration of $20 \mathrm{mg} / \mathrm{m}^{2}$ (see the results presented in Figure 3), we had to focus on adults from FARM1 for this experiment. Lesser mealworms from this population survive exposure to cyfluthrin concentrations encountered in the field (as recommended applications contain $20 \mathrm{mg}$ cyfluthrin/ $\mathrm{m}^{2}$, C. Salin et al., 2003), which thus allowed working with this concentration without incurring selection of individuals due to mortality or locomotor deficits during the pre-exposure period.

For this experiment, three temperature conditions were used: (i) constant $26{ }^{\circ} \mathrm{C}$ for eight days (control), $18 \mathrm{~h}$ at $26^{\circ} \mathrm{C}$ daily interrupted by exposures of $6 \mathrm{~h}$ at (ii) $32^{\circ} \mathrm{C}$ (low heat spike), or (iii) $38^{\circ} \mathrm{C}$ (high heat spike). The exposure ran over eight days in darkness. Glass Petri dishes were prepared with four doses of cyfluthrin $\left(0,5,10\right.$ or $20 \mathrm{mg}$ cyfluthrin $\left./ \mathrm{m}^{2}\right)$ as described above, including addition of food and water. Then, 30 adults from FARM1 were added to each dish, and dishes of every pesticide dose were placed into each of the three temperature cabinets (MIR 154 Panasonic 
Incubators), resulting in a total of four different pesticide exposures at three different temperature regimes.

After eight days, and 17 hours after the last peak of heat, the Petri dishes were removed from the temperature cabinets, and the beetles were directly exposed to either -6 or $+42.5^{\circ} \mathrm{C}$ for $2 \mathrm{~h}$, in darkness (Supplementary File 2). Extreme temperature exposure was performed as described above (section 2.2.1.), including testing the recovery of at least 40 individuals to each combination of treatment (temperature regime, insecticide dose, and temperature regime $\mathrm{x}$ insecticide dose), but the temperature of the recovery room was higher (approx. $24{ }^{\circ} \mathrm{C}$ instead of $20^{\circ} \mathrm{C}$ ).

\subsection{Data treatment}

The recovery time of every single individual was used to compute the temporal recovery curves using Kaplan Meier estimates computed in $\mathrm{R}$ version 3.5.2, using the Survminer package (Kassambara and Kosinski 2018; R Core Team 2013). The probability of recovery at any given time point therefore represents the proportion of individuals that have recovered by that time. Pairwise comparisons using Log-Rank test with adjusted P-values (Benjamini and Hochberg 1995) were performed post-hoc, with a significance value of 0.05 . Generalized linear models (GLMs) with logit link function for proportions outcome (i.e. number of active versus impaired or immobile individuals per dish) were run on data reporting the state of animals after eight days of exposure to the different temperature regimes and pesticide doses. The effect of each variable (temperature, and insecticide dose), and their interactions, were analysed using the analysis of deviance (Anova function in the car package (Fox and Weisberg 2019)). We assume that this insecticide and heat peaks have different modes of actions, meaning that their individual- and interaction effects on $A$. diaperinus adults are assumed to be multiplicative. Differences among the treatments were finally analysed by Sidak's multiple comparisons using the emmeans and multcompView packages (Graves, Piepho, and Selzer 2019; Lenth 2020), with a significance value of 0.05 .

\section{Results}

\subsection{Characterization of the thermal tolerance of the insects from different populations}

The recovery probability over time of adult $A$. diaperinus was dependent on the exposure duration to hot or cold temperature extremes (Figures 1 and 2; Supplementary File 3). Adults from LAB 
recovered more slowly than adults from the poultry house-collected populations for all durations of exposure at $42.5^{\circ} \mathrm{C}(\mathrm{P} \leq 0.05)$, and all but 30 minutes exposure at $-6{ }^{\circ} \mathrm{C}(\mathrm{P} \leq 0.05)$ (Supplementary File 3). After a $30 \mathrm{~min}$ exposure at $-6{ }^{\circ} \mathrm{C}$, the recovery from $L A B$ was comparable to that measured from the three other populations $(P \geq 0.05)$; after 1 hour exposure at $42.5^{\circ} \mathrm{C}$, the recovery curve of LAB was also similar to FARM3 $(P=0.33)$. When the duration of exposure to heat or cold temperatures was increased, the proportion of insects that fully recovered was decreased and the duration of recovery was prolonged (Figures 1 and 2).

The recovery probability of the lesser mealworms from FARM 1 and FARM 2 after they were exposed to heat $\left(42.5^{\circ} \mathrm{C}\right)$ was similar for all experimental conditions. When exposed to temperature extremes for $0.25,0.5,1,2$, or $3 \mathrm{~h}$, insects from FARM3 were characterised by a lower recovery probability as compared with the two other poultry house-collected populations (Figure 1).

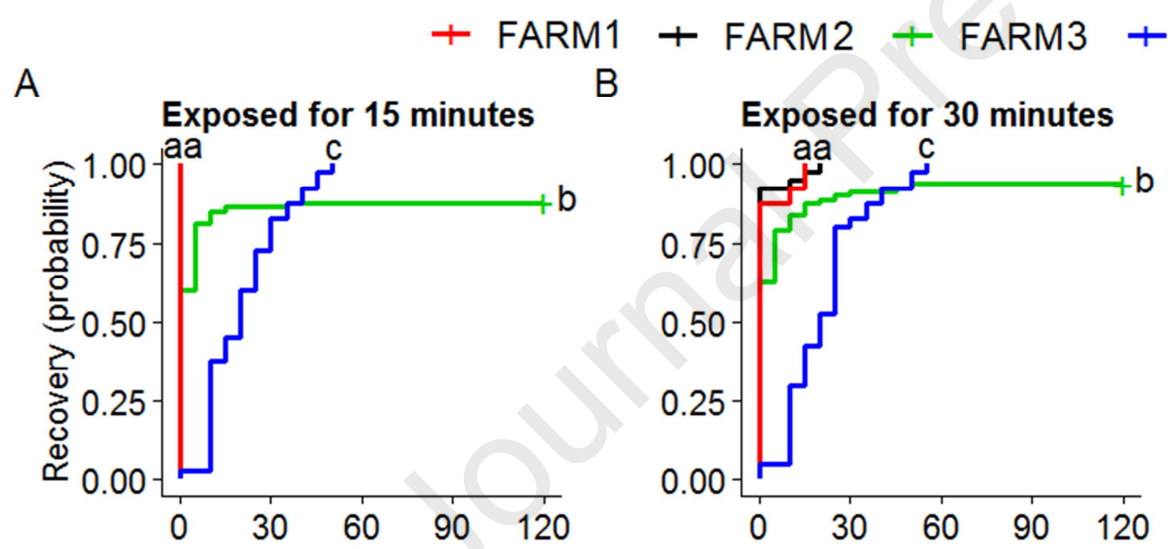

D

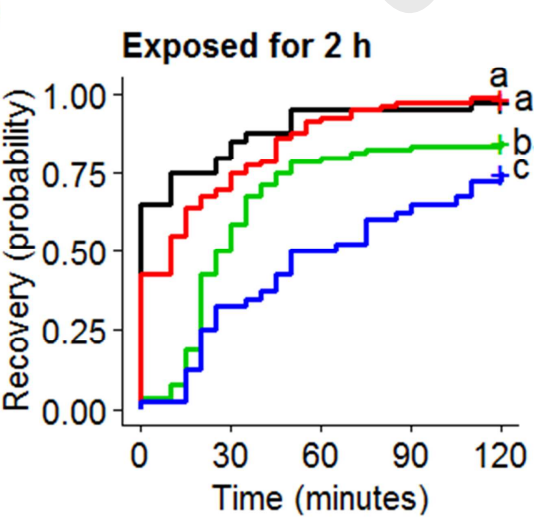

E
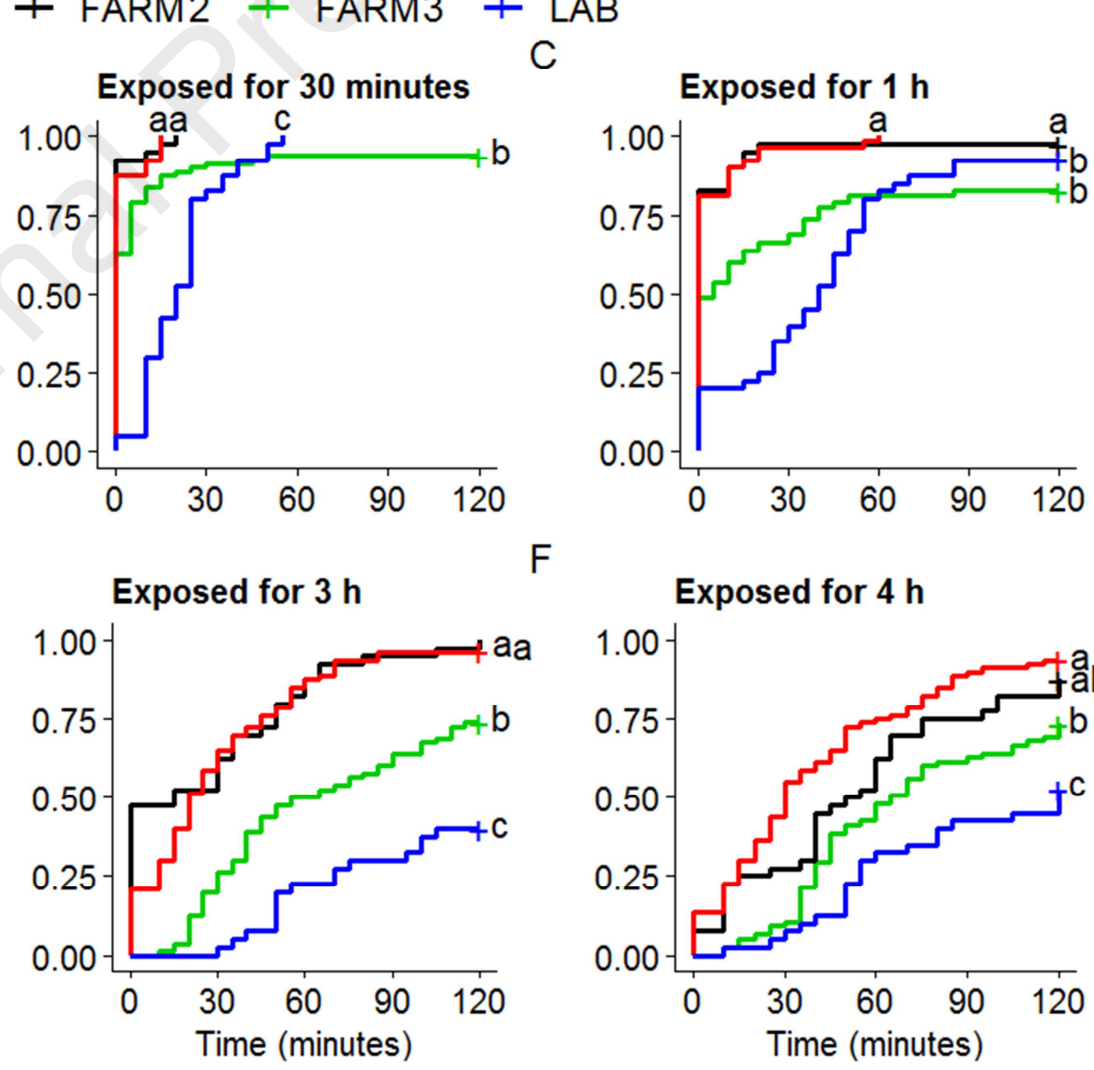

F

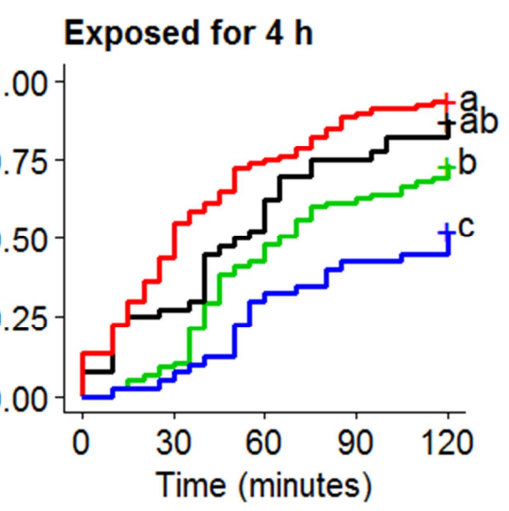

Figure 1. Recovery probability of individuals from four different populations of $A$. diaperinus exposed at $42.5^{\circ} \mathrm{C}$ for six different durations: A) 0.25 hour (overall $\mathrm{P}<0.001$ ); B) 0.5 hour (overall $\mathrm{P}$ $<0.001$ ); C) 1 hour (overall $\mathrm{P}<0.001$ ); D) 2 hours (overall $\mathrm{P}<0.001$ ); E) 3 hours (overall $\mathrm{P}<0.001$ ); F) 
4 hours (overall $P<0.001$ ). The red lines represent insects from FARM1, the black lines represent the insects from FARM2, the green lines represent the insects from FARM3, and the blue lines represent the insects from $L A B$. Different letters indicate differences among the recovery probability

A

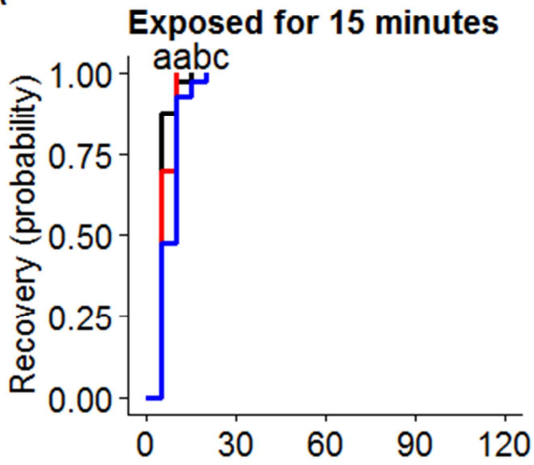

$\mathrm{D}$

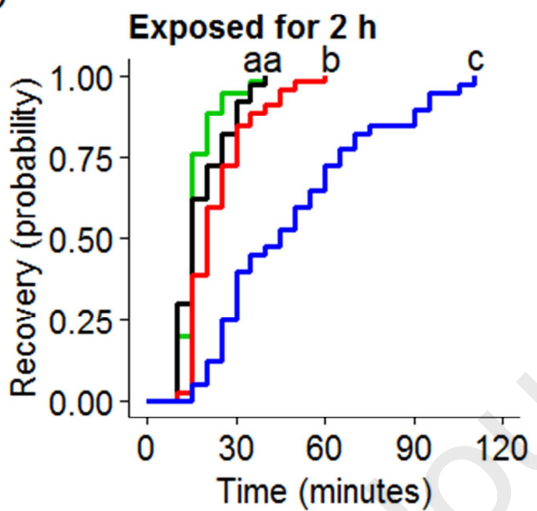

\section{E}

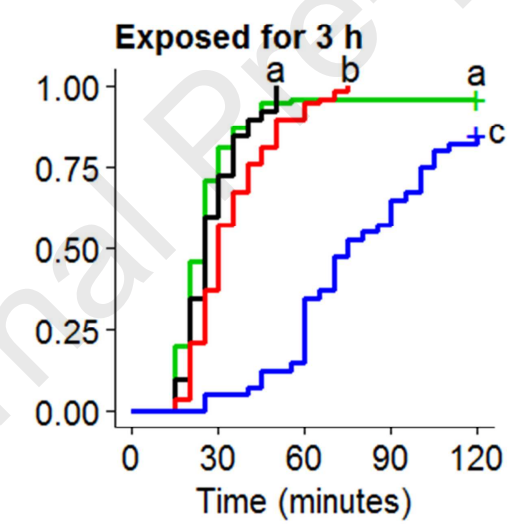

$L A B$

C

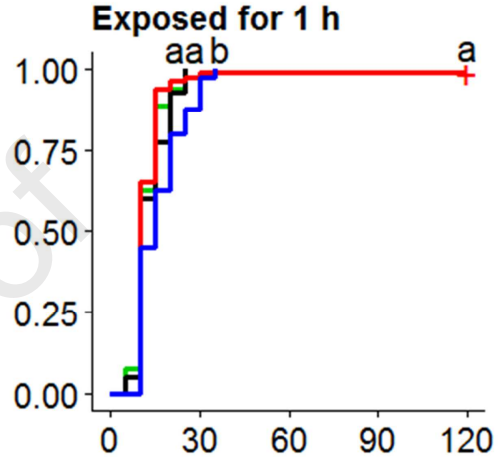

$\mathrm{F}$

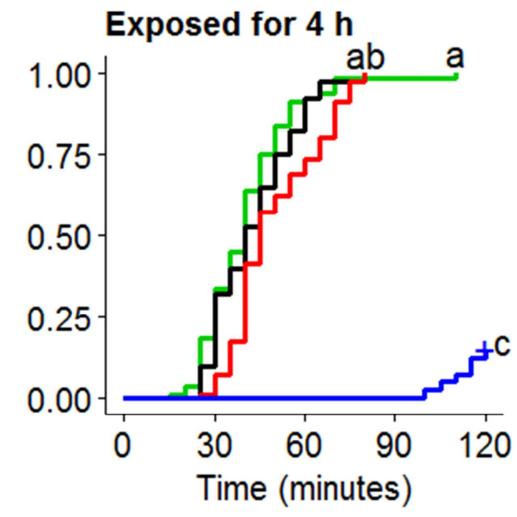

Figure 2. Recovery probability of individuals from four different populations of $A$. diaperinus exposed at $-6{ }^{\circ} \mathrm{C}$ for six different durations: A) 0.25 hour (overall $P<0.001$ ); B) 0.5 hour $(P=0.074$ ); C) 1 hour (overall $P<0.01$ ); D) 2 hours (overall $P<0.001$ ); E) 3 hours (overall $P<0.001$ ); F) 4 hours (overall $P<0.001$ ). The red lines represent insects from FARM1, the black lines represent the insects from FARM2, the green lines represent the insects from FARM3, and the blue lines represent the insects from $L A B$. Different letters indicate differences among the recovery probability curves within each exposure duration.

\subsection{Effect of daily heat spikes and cyfluthrin exposure}

309 The number of active lesser mealworms was significantly reduced when insects were exposed to cyfluthrin at constant temperature $\left(26^{\circ} \mathrm{C}\right)$ as compared with control insects $(\mathrm{P}<0.05(95 \%$ confidence level)) for all populations (Figure 3), except for FARM1 (Figure 3, A; Supplementary File 
3). Sidak's multiple comparisons post-hoc tests following a two-way ANOVA showed that the insecticide cyfluthrin and daily heat spikes ( $18 \mathrm{~h}$ at $26^{\circ} \mathrm{C}$ followed by $6 \mathrm{~h}$ period at $38^{\circ} \mathrm{C}$ for 8 days) significantly decreased the proportion of active insects as compared with control and heat treatment conditions ( $\mathrm{P}<0.05)$ for all populations (Figure 3A-D; Supplementary File 3). Yet, the proportion of insects that were scored as active remained close to $100 \%$ for FARM1. The proportion of insects scored as active significantly differed among the "Cyfluthrin" and "Daily heat spikes \& Cyfluthrin" treatments for FARM2 $(P<0.05)$ and LAB $(P<0.05)$. There was no significant interaction between daily heat spikes and cyfluthrin for any of the populations ( $P=0.28$ or higher) (Figure 3, A-
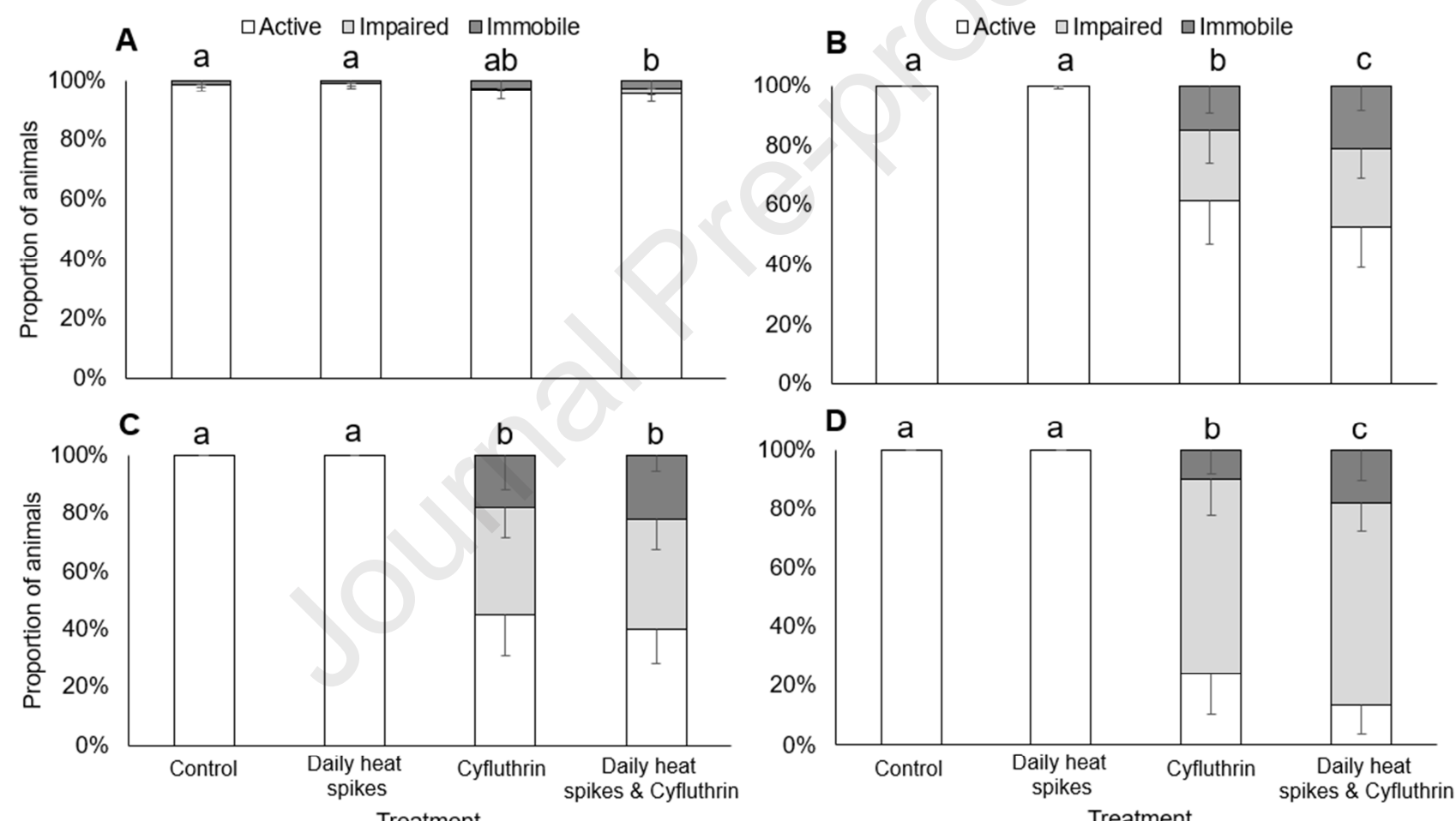

Figure 3. Status of adult $A$. diaperinus from populations A) FARM1, B) FARM2, C) FARM 3 after they were exposed for eight days to control conditions (constant $26^{\circ} \mathrm{C}$ ), daily heat spikes $\left(26^{\circ} \mathrm{C}\right.$ for $18 \mathrm{~h}$, $38^{\circ} \mathrm{C}$ for $\left.6 \mathrm{~h}\right)$, cyfluthrin $\left(20 \mathrm{mg} / \mathrm{m}^{2}\right)$ or daily heat spikes and cyfluthrin and D) LAB after eight days of same exposure treatments, but with a cyfluthrin concentration of $0.5 \mathrm{mg} / \mathrm{m}^{2}$. Different letters indicate differences among the number of active insects within each population. 
The recovery probability of adult $A$. diaperinus from FARM1 decreased with increasing doses of

331 cyfluthrin after the insects were maintained for eight days under different temperature regimes and

332 cyfluthrin concentrations prior to extreme temperature exposure $(P<0.001)$ (Figure 4;

333 Supplementary File 3). This was particularly evident for beetles exposed to heat $\left(42.5^{\circ} \mathrm{C}\right)$ (Figure 4).

334 Pre-exposure to a daily heat spike for eight days (Figure 4, B-C) accelerated the recovery of the 335 insects after they were exposed at $42.5^{\circ} \mathrm{C}$ for $2 \mathrm{~h}$, as compared with animals exposed at constant 26

$336{ }^{\circ} \mathrm{C}$ (Figure 4, A; Supplementary File 3). Conversely, the recovery curves remained comparable for 337 insects that were exposed to extreme cold $\left(-6^{\circ} \mathrm{C}\right.$ for $2 \mathrm{~h}$; Figure $\left.4, \mathbf{D}-\mathbf{F}\right)$, even though they were previously subjected to different heat spikes for 8 days.
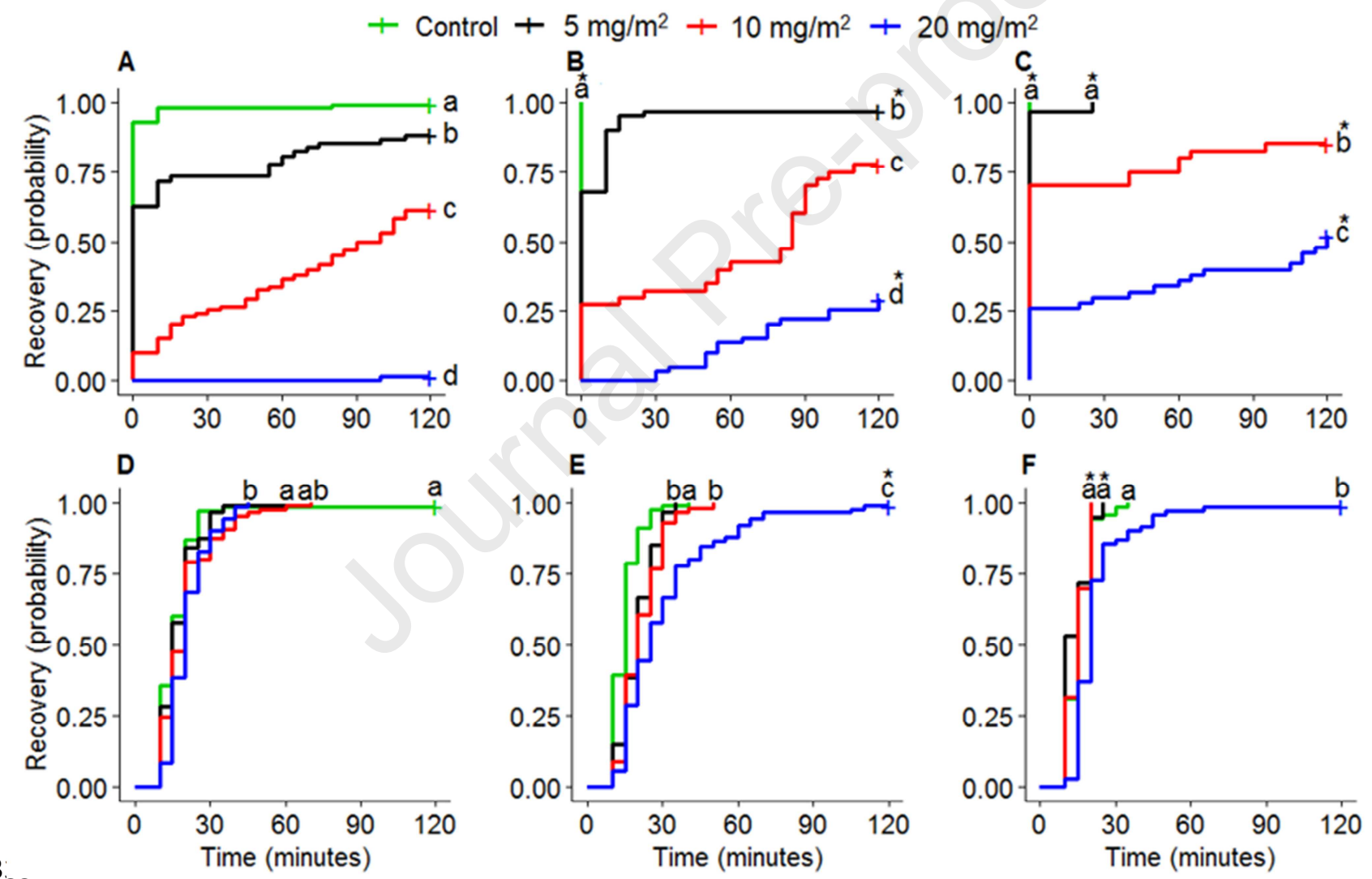

Figure 4. Recovery probability of $A$. diaperinus from FARM1 observed every 5 minutes after a 2-hour exposure at $42.5^{\circ} \mathrm{C}(A, B$ and $C)$ or $-6{ }^{\circ} \mathrm{C}(D, E$ and $F)$. Before the test, the insects were exposed to different temperature regimes: (A) and (D) constant $26^{\circ} \mathrm{C}$; (B) and (E) $26{ }^{\circ} \mathrm{C}$ daily interrupted by $6 \mathrm{~h}$ at $32{ }^{\circ} \mathrm{C} ;(\mathbf{C})$ and $(\mathbf{F}) 26^{\circ} \mathrm{C}$ daily interrupted by $6 \mathrm{~h}$ at $38^{\circ} \mathrm{C}$. For each temperature regime, the insects were exposed to four different concentrations of the insecticide cyfluthrin: 0 (control), 5 (black lines), 10 (red lines) or 20 (blue lines) mg cyfluthrin $/ \mathrm{m}^{2}$. Stars $\left({ }^{*}\right)$ represent significant differences between the marked curve and the curve of the same colour drawn in Fig. 4A (constant temperature 
regime used as the reference recovery probability). Different letters indicate differences among the recovery probability curves within each temperature pre-treatment group.

\section{Discussion}

\subsection{Characterization of the thermal tolerance of the insects from different populations}

In this study, we were interested in comparing the basal thermal tolerance of adult A. diaperinus from four populations through assessments of their ability to recover from different durations of exposure to cold or heat. Adults from FARM1 and FARM2 were characterized by the greatest ability to recover from thermal stress, in particular to heat exposure, while laboratory-reared adults exhibited the lowest thermal tolerance, in line with our expectations. The thermal plasticity of lesser mealworm populations is also consistent with the wide range of temperatures that can occur during a poultry house production cycle. Acclimation or adaptation to thermally variable habitats may widen the temperature tolerance range, as reported from other insect models (reviewed in Colinet et al. 2015; Lachenicht et al. 2010). For instance, working with Drosophila melanogaster reared at varying temperature regimes, Bozinovic et al. (2011) observed a reduction of the number of flies entering into chill or heat coma when transferred to extreme temperatures, as compared with flies reared at constant temperature. Overgaard, Hoffmann, and Kristensen (2011) evidenced that acclimation of $D$. melanogaster to variable temperatures increased tolerance to both low and high thermal stress. In addition, these authors showed that populations originating from temperate areas exhibited a wider thermal tolerance than those sampled from more thermally stable tropical environments. In sum, the lower thermal tolerance of adult $A$. diaperinus from LAB is consistent with the available literature, and the hypothesis that poultry house-collected insects have higher recovery probabilities than laboratory-bred individuals was confirmed.

In this work, insects from FARM3 exhibited a significantly lower thermal tolerance than their counterparts sampled from the other two poultry farms. However, many other environmental factors experienced by the insects in the poultry farm, such as $\mathrm{pH}$ and ammonia concentration in the litter, or the presence and diversity of bacteria and viruses which trigger immune responses that can alter the performance of other physiological traits, may have shaped the thermal tolerance of the insects from poultry farms. Further, we can also expect the populations to be genetically distinct 
from each other. As a result, variance in thermal tolerance among the insects from the three farm populations is not surprising (Miller, Mohrenweiser, and Bell 2001).

\subsection{Effect of daily heat spikes and cyfluthrin exposure}

The previous experiment reported differences in the thermal tolerance among populations of $A$. diaperinus. In particular, insects from FARM1 and FARM2 exhibited slightly higher capacity to recover from heat exposure, suggesting that they would be better able to cope with daily heat spikes, while insects from the LAB population should have had the lowest ability to deal with peaks of heat. Yet, none of the populations were visibly affected by the daily heat spikes on their own.

Insects from FARM1 were capable of coping with the investigated dose of cyfluthrin at constant temperature, while this condition was detrimental for the three other populations. As expected, adults of $A$. diaperinus from LAB were more sensitive to the insecticide than those of the three FARM populations. Differences in cyfluthrin resistance have already been reported in A. diaperinus populations from Australia (Lambkin and Rice 2009), where resistance was generally related to the extent and frequency of cyfluthrin applications experienced by the insects. Similarly, Chernaki-Leffer et al. (2011) found strains of $A$. diaperinus of different pesticide (cypermethrin, dichlorvos and triflumuron) susceptibility in Brazil, and Hamm et al. (2006) found strains of $A$. diaperinus with different pesticide (cyfluthrin and tetrachlorvinphos) resistance in the United States. The latter authors suggested that resistance alleles are present in the resistant populations of the lesser mealworm, as may have been the case with our poultry house collected insects.

While daily heat spikes alone did not affect the recovery of the insects of the four tested populations, the combination of insecticide and daily heat spikes significantly reduced the number of active individuals in two (FARM2 and LAB) out of the four assayed populations. Warm temperatures have been found to decrease the toxicity of the pyrethroids cypermethrin and deltamethrin in the fly Musca domestica (Khan and Akram 2014), and in the Spotted bollworms Earias vittella exposed to pyrethroids at higher temperature regimes (Satpute et al. 2007). Yet, these authors used constant temperatures in their experiments. The increased negative effects of the insecticide for adult $A$. diaperinus experiencing a daily heat spike of 6 hours is consistent with the findings of several other studies (Delnat et al. 2019; Willming, Qin, and Maul 2013; Zhu, Sengonca, and Liu 2006), who found increasing pesticide toxicity in insects subjected to daily bouts of high 
temperatures. For instance, daily thermal fluctuations as low as $5{ }^{\circ} \mathrm{C}$ increased toxicity of chlorpyrifos in damselfly larvae (Verheyen and Stoks 2019). The synergistic effects of thermal variations and insecticides may occur under large thermal variations only, as reported in the vector mosquitoes Culex pipiens (Delnat et al. 2019). The magnification of the effects of pyrethroids on $A$. diaperinus we have found emphasizes the importance of considering daily thermal variations and heat spikes in risk assessments of the sensitivity of biodiversity to pollution under different scenarios of climate change, although a higher constant temperature equivalent of the average temperature experienced by animals exposed to daily heat peaks would allow us to make stronger conclusions on this point. At higher temperatures, pesticide uptake may be increased, as found by Lydy, Belden, and Ternes (1999) and Buchwalter, Jenkins, and Curtis (2003). In parallel, elimination rates of the toxicants, for example through temperature-dependent activation of enzymes, should also be enhanced at warmer conditions. In sum, the available literature and our results could indicate a promotion of insecticide resistant genotypes with increasing occurrence of extreme weather events, which is consistent with documented links between climatic variables and evolution of pesticide resistance in arthropod pests (Maino, Umina, and Hoffmann 2018). Facilitation of insecticide resistance as a result of climate change could be a result of pleiotropy, shared genetic mechanisms or genetic linkage (Pu, Wang, and Chung 2020).

\subsection{Effect of daily heat spikes and cyfluthrin exposure on recovery from exposure to extreme} temperatures

Using adult $A$. diaperinus from FARM1, we tested how the sensitivity to extreme temperatures was affected by thermal and insecticide pre-treatments. We expected higher proportion of recovery and faster recovery from heat stress in insects exposed to a daily heat spike over eight consecutive days, as extreme temperature tolerance is readily modified by a thermal conditioning processes, even in the short-term (Chidawanyika and Terblanche 2010; Kingsolver et al. 2016; Weldon, Terblanche, and Chown 2011). Our results are consistent with this expectation for heat-shocked insects. Daily peaks at high temperatures may have acclimated the insects to heat, which does not necessarily prepare them for cold exposures. Indeed, cold tolerance requires different mechanisms compared to heat tolerance, by for instance increasing membrane fluidity instead of decreasing it (Neven 2000; Teets and Denlinger 2013). This can explain why heat pre-exposures did not consistently affect cold tolerance in this experiment. Similarly, it has been shown that acclimation to low temperature 
increased cold tolerance, but did not affect heat tolerance in Drosophila melanogaster (Overgaard et al. 2007).

For insects exposed to extreme heat, insecticide pre-treatment significantly reduced recovery probability, both by generally increasing the recovery time and the number of beetles that did not recover within the recovery period. In fact, beetles pre-exposed to the sublethal dose of $20 \mathrm{mg} / \mathrm{m}^{2}$ at control temperature never recovered from the applied sublethal heat exposure. We also observed that even a relatively low exposure dose ( $5 \mathrm{mg}$ cyfluthrin $\left./ \mathrm{m}^{2}\right)$ had a significant effect on the recovery probability of the individuals, thus providing supporting evidence for toxicant-induced climate sensitivity (Hooper et al. 2013; Moe et al. 2013) in adult $A$. diaperinus. Several studies have shown that an increase in temperature generally enhances negative effects of contaminants (Noyes et al. 2009; Noyes and Lema 2015), but the number of studies that have tested the effects of insecticide pre-treatments is rather limited as compared with investigations assessing the effects of simultaneous exposures. Importantly, when working sequentially, i.e. by applying one stress before the other, results can greatly vary depending on the specific chemical investigated (Matzrafi 2019). Here, we can hypothesize that coma, which is related to nerve dysfunction, through decreased membrane potential and reduced excitability of the neuromuscular system, occurs more quickly and severely during heat treatment after cyfluthrin exposure, as cyfluthrin is an inhibitor of nerve cell sodium channels. Meanwhile, further research is required to reveal the mechanistic processes explaining the recovery patterns we observed here. For the insects exposed to extreme cold, the effect was only observable after exposure to a dose that is close to the one recommended for use of the insecticide in commercial products ( $20 \mathrm{mg}$ cyfluthrin $/ \mathrm{m}^{2}$ ). A previous study did not find an effect of pesticide exposure on freeze tolerance in an earthworm (Bindesbøl et al. 2009), which indicates that cold tolerance is not as sensitive to insecticide exposure as heat exposure.

Our results also fit well with effects of pesticide exposure on temperature tolerance found in other studies. For example, Op de Beeck, Verheyen, and Stoks $(2017,2018)$ found that damselfly larvae that were sensitive to the pesticide chlorpyrifos also showed a reduction in heat tolerance after exposure to the pesticide. The authors also showed that the reduction in heat tolerance was smaller when the animals had been pre exposed to higher temperatures, a finding that is in line with our study. In addition, Delnat et al. (2019) found that pesticide exposure decreased temperature tolerance in mosquito larvae and males, and Meng, Delnat, and Stoks (2020) showed that pesticide 
465

466

467

468

469

470

471

472

473

474

475

476

477

478

479

480

481

482

483

484

485

486

487

488

489

490

491

492

493

exposure prior to experiencing a heat spike reduced heat tolerance of mosquito larvae. This reduction in temperature tolerance following pesticide exposure is also true for other taxa, as critical thermal maximum was also reduced in fishes after exposure to endosulfan and chlorpyrifos (Heath et al. 1994; Patra et al. 2007).

The effect of fluctuating temperature regime was also observable in animals who had been exposed to insecticide prior to extreme temperature treatment. It is however difficult to determine whether the observed increase in thermal tolerance after varying temperature regimes was caused by increased tolerance to extreme heat, to insecticide exposure or a combination of the two (Oliver and Brooke 2017). Further research into pesticide uptake and elimination in the animals in the course of this experimental setup would be of interest to further elucidate the processes behind the observed effect.

\section{Conclusion}

The present work reports that populations of the lesser mealworms have distinct abilities to recover from thermal and insecticide stress, and their interactions. This finding emphasises the importance of designing experiments including several populations when making assessments of the sensitivity of a given species to environmental factors, and more particularly when these data nourish models aiming at forecasting the future of biodiversity. No synergistic interaction was found when the lesser mealworms were jointly subjected to daily heat spikes and cyfluthrin; yet, this type of experimental procedure, which simulates the conditions that could be experienced by free-ranging organisms in natural and anthropogenic environments, increase the ecological realism of the study. This is even truer in a global warming context, as daily heat spikes are expected to become more frequent in several habitats. Here, we also found the importance of working with field-collected insects. The thermal tolerance and sensitivity to insecticide of the laboratory population was very different than that of the field specimens, meaning that different conclusions would be drawn if working with the former population only. Finally, and in line with earlier investigations, our study pointed out the importance of considering the effects of multiple stressors, and the lasting effects they can have on other traits of the insects.

\section{Acknowledgements}


We would like to thank Guillaume Weecxsteen, Héloïse Moullec and Baptiste Vasseur for their contribution in collecting data for this study. We also thank Maxime Dahirel, Mathias Holmstrup and

496 Stine Slotsbo for interesting discussions on this work. This study was supported by France-Agri-Mer 497 (Research grant 'Teneblimit'), and by the International Research Project (IRP) 'Phenomic responses of invertebrates to changing environments and multiple stress (PRICES) funded by InEE-CNRS.

\section{Supplementary File 1}

501 To begin this study, we had to test the effects of different temperatures on the recovery capacity of 502 adult Alphitobius diaperinus, that is, the effects of exposure to extreme temperatures (cold, heat) on 503 the recovery ability and duration of the individuals.

504 Insects from the population FARM1 were used to describe the general temperature tolerance of the 505 species, and to find temperature exposures that would cause the adults to enter chill coma, yet 506 keeping the ability to recover (capacity to regain full movement) afterwards. Four to eight replicates 507 of 10 individuals in each container (test tube with rubber cap) were created for each exposure 508 temperature, starting at $-4{ }^{\circ} \mathrm{C}$ for cold exposure, and at $+42{ }^{\circ} \mathrm{C}$ for heat. At the end of the thermal 509 treatment, the insects were directly transferred to Petri dishes and observed every 5 minutes for $2 \mathrm{~h}$. 510 Each observation period lasted for up to 40 seconds, and individuals were registered as either

511 "Immobile, Impaired" or "Recovered". Animals were characterized as "Recovered" when they had 512 regained the ability to move normally. The temperature both in the cryothermostat and the room 513 where recovery observations took place was monitored using iButtons ${ }^{\circledR}$ (iButtonLink, LLC., 514 Whitewater, USA). 
Since thermal performance curves are often steep at high temperature extremes, and change less quickly at cold temperature extremes (Huey and Stevenson 1979; Sinclair et al. 2016), we used small increments of temperature in the heat exposure experiments $\left(0.5^{\circ} \mathrm{C}\right)$ and larger increments $\left(2{ }^{\circ} \mathrm{C}\right)$

518 for cold exposure. When having run three temperatures for a duration of 2 hours, we were able to see the temperatures that would best describe the effects of different durations of exposure on the thermal tolerance of adult $A$. diaperinus from different populations. These experimental conditions were also used for comparing the effects of different daily heat spikes and insecticide exposures prior to extreme temperature exposure.

In Appendix Figure 1, we see that the insects recovered very quickly from the least extreme investigated temperatures; exposure to $+42{ }^{\circ} \mathrm{C}$ did not even elicit heat coma from which the animals could recover. Furthermore, the animals showed a low ability to recover from the most extreme temperatures used: after an exposure to $+43{ }^{\circ} \mathrm{C}$, many insects were not able to recover within the recovery period (Appendix Figure 1, A), and after 2 hours at $-8{ }^{\circ} \mathrm{C}$ it took around 45 minutes before half of the individuals had recovered (Appendix Figure 1, B).

A

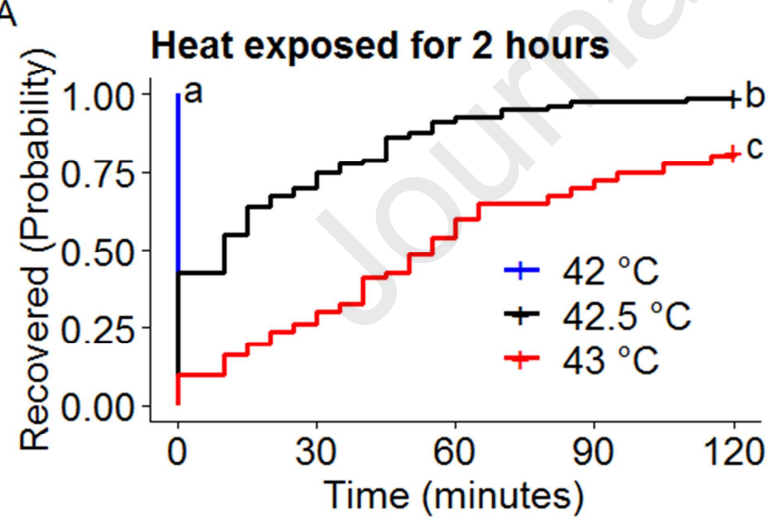

B

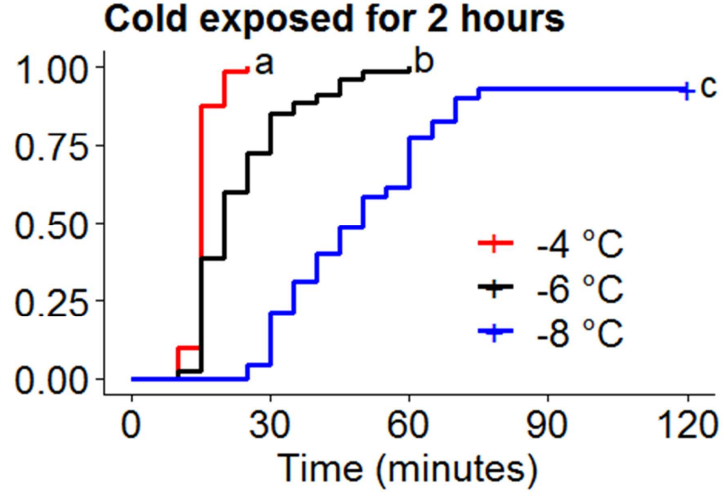

529

Appendix Figure 1 illustrates the recovery time of adult Alphitobius diaperinus from FARM1 after exposure to different extreme temperatures (represented by different coloured lines) for 2 hours. A) Recovery curve of individuals exposed to extremely warm temperatures ( 42 to $43{ }^{\circ} \mathrm{C}$ ) (overall $\mathrm{P}<$ $0.001)$. B) Recovery trajectory of individuals exposed to extremely cold $\left(-4\right.$ to $\left.-8{ }^{\circ} \mathrm{C}\right)$ temperatures (overall $\mathrm{P}<0.001$ ).

From these results, it can be concluded that adults of $A$. diaperinus have an extreme temperature tolerance that is within the range that commonly characterizes insects (Addo-Bediako, Chown, and 
Gaston 2000). We also see that the changes in recovery time with changing temperature follows a pattern typical from thermal performance curves (Colinet et al. 2015; Huey and Stevenson 1979).

539 Specifically, great changes in thermal tolerance happens across a narrower temperature range at 540 extreme heat (here between 42 and $43^{\circ} \mathrm{C}$ ) compared to extreme cold (here -4 to $-8^{\circ} \mathrm{C}$ ). We also 541 note that adults of $A$. diaperinus were stressed (went into chill coma), but all individuals recovered 542 from sudden exposure at $42.5{ }^{\circ} \mathrm{C}$ and $-6{ }^{\circ} \mathrm{C}$. Therefore, these conditions represent suitable 543 temperatures for comparing differences in recovery time among populations or treatment groups.

Populations

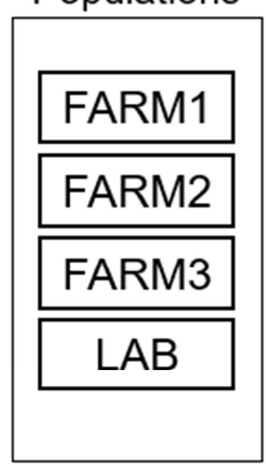

\section{Exposure}

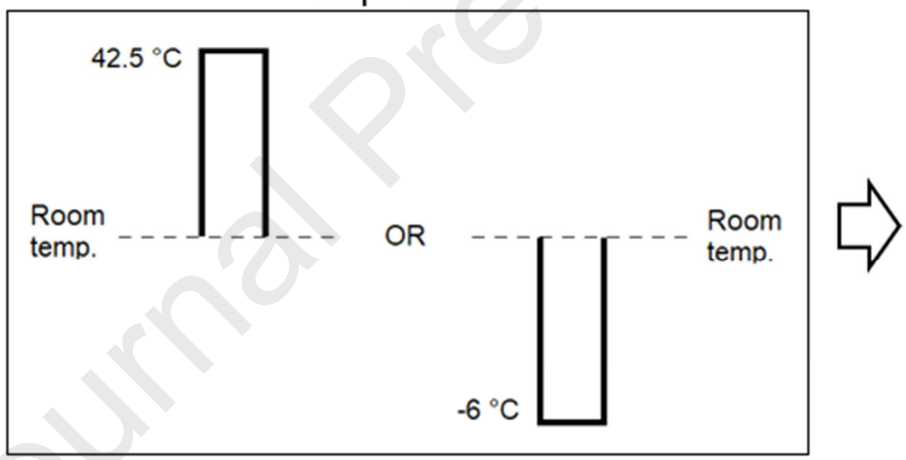

Observation

Room

temp. $2 \mathrm{~h}$

Recovery 
Exposure

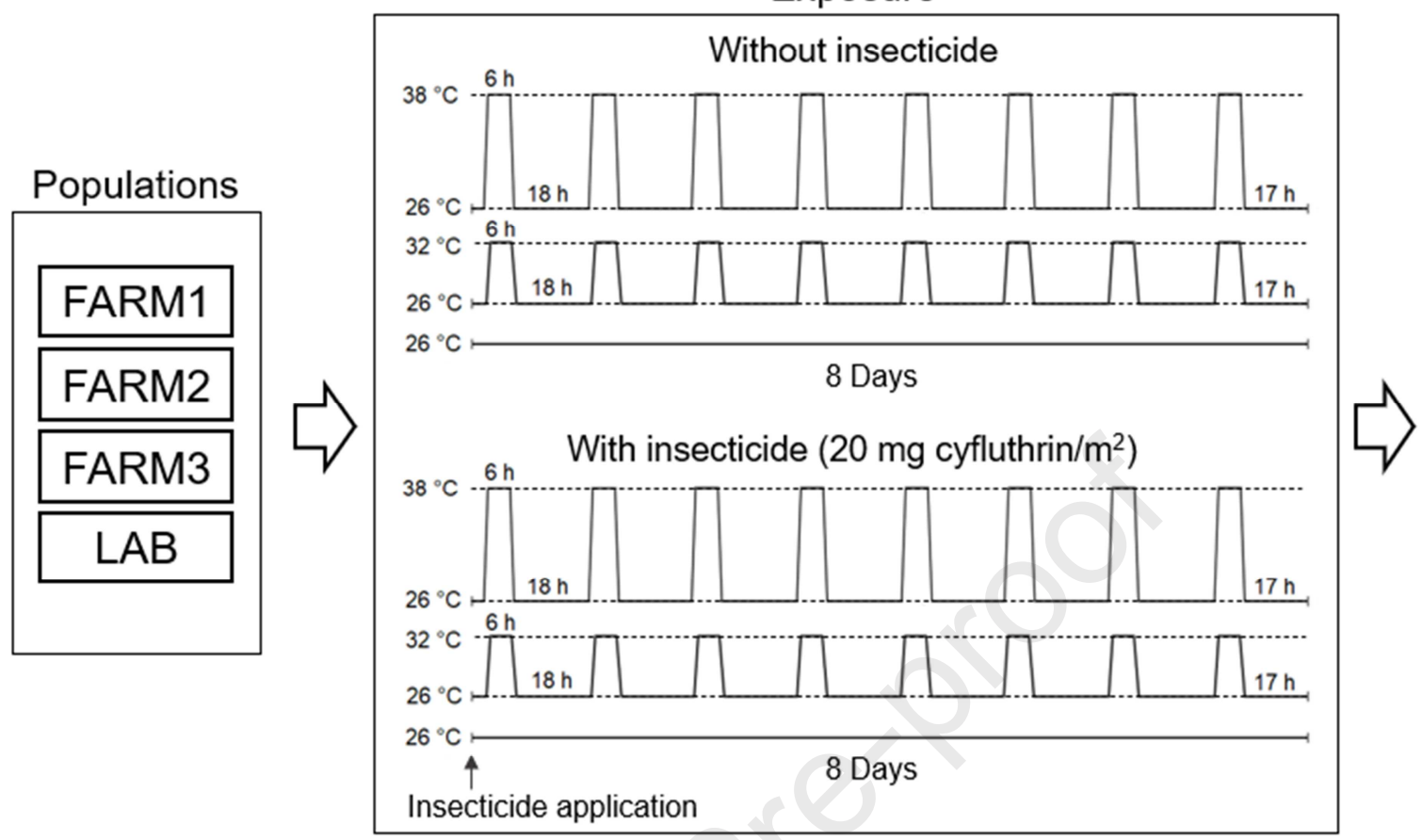

Observation

$26^{\circ} \mathrm{C} \underset{1 \text { minute }}{ }$

Appendix figure 2 Schematic presentation of the design of experiment 2

Exposure 1

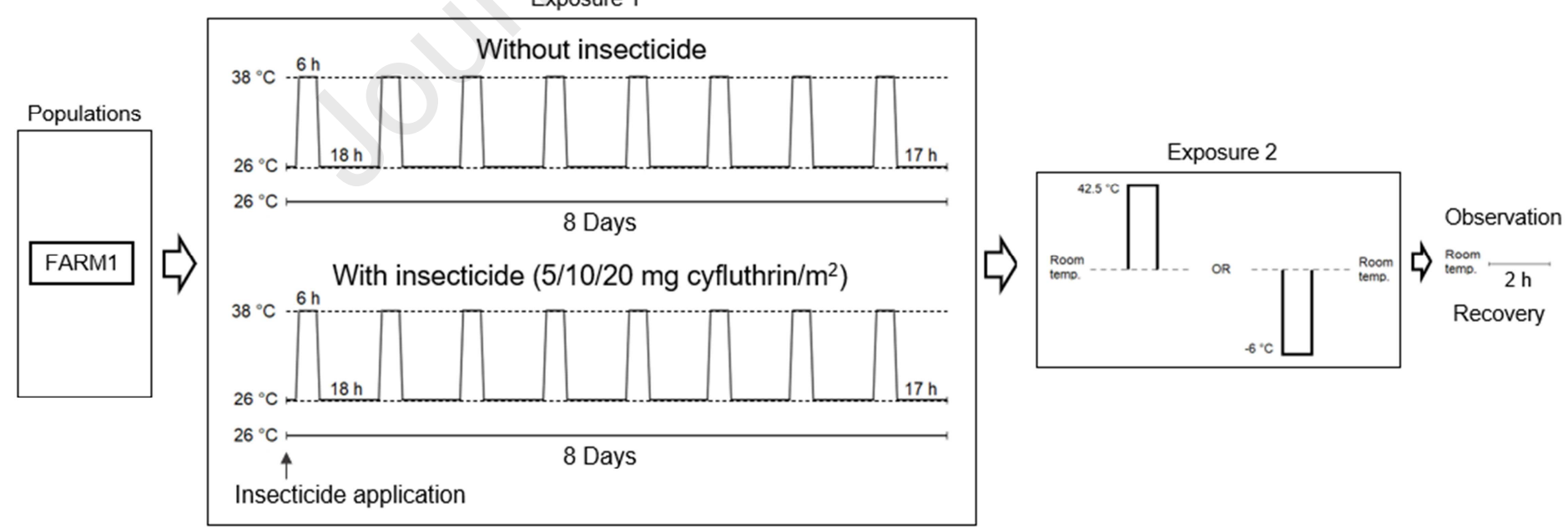

Appendix figure 3 Schematic presentation of the design of experiment 3. The second part of the experiment (Exposure 2 and recovery observations) was identical to experiment 1, and can be seen in larger version in Appendix figure 1. 


\section{Supplementary File 3}

566 Appendix table 1: Detailed statistical results of experiment 1 (corresponding to results presented in

567 Figures 1 and 2 in the main text of the article). Pairwise comparisons (Log-Rank tests; graphs A-F)

568 were performed using the Survdiff function in R. Significant $p$ values are presented in bold.

\begin{tabular}{l|rrr}
\multicolumn{3}{c}{ Recovery from extreme heat $\left(42.5^{\circ} \mathrm{C}\right)$} \\
Duration & \multicolumn{3}{|c}{15 minutes exposure } \\
\hline Population & FARM 3 & FARM 2 & FARM 1 \\
\hline FARM 2 & $4.90 E-06$ & - & - \\
FARM 1 & $4.90 E-06$ & 1.0000 & - \\
LAB & $0.004<2.00 E-16$ & $<2.00 E-16$
\end{tabular}

\begin{tabular}{l|rrr} 
Duration & \multicolumn{4}{|c}{30 minutes exposure } \\
\hline Population & FARM 3 & FARM 2 & FARM 1 \\
\hline FARM 2 & $\mathbf{0 . 0 0 2 0}$ & - & - \\
FARM 1 & $\mathbf{0 . 0 0 2 0}$ & 0.8152 & -
\end{tabular}

\begin{tabular}{l|rrr}
\multicolumn{4}{c}{ Recovery from extreme cold $\left(-6^{\circ} \mathrm{C}\right)$} \\
Duration & \multicolumn{4}{c}{15 minutes exposure } \\
\hline Population & FARM 3 & FARM 2 & FARM 1 \\
\hline FARM 2 & 0.7078 & - & - \\
FARM 1 & $\mathbf{0 . 0 1 0 5}$ & 0.1059 & - \\
LAB & $\mathbf{7 . 6 0 E - 0 6}$ & $\mathbf{0 . 0 0 1 3}$ & $\mathbf{0 . 0 0 8 2}$
\end{tabular}

\begin{tabular}{l|rrr} 
Duration & \multicolumn{4}{|c}{30 minutes exposure } \\
\hline Population & FARM 3 & FARM 2 & FARM 1 \\
\hline FARM 2 & 0.6470 & - & - \\
FARM 1 & 0.1430 & 0.1430 & -
\end{tabular}


$L A B$

0.0004

$3.20 \mathrm{E}-14<2.00 \mathrm{E}-16$

\begin{tabular}{l|rrl} 
Duration & \multicolumn{3}{|c}{1 hour exposure } \\
\hline Population & FARM 3 & FARM 2 & FARM 1 \\
\hline FARM 2 & $\mathbf{0 . 0 0 0 1}$ & \multicolumn{3}{|c}{-} \\
FARM 1 & $\mathbf{4 . 9 0 E - 0 7}$ & 0.9446 & - \\
LAB & 0.3298 & $\mathbf{2 . 0 0 E - 0 8}$ & $\mathbf{2 . 7 0 E - 1 2}$
\end{tabular}

\begin{tabular}{l|rrr} 
Duration & \multicolumn{3}{|c}{ 2 hours exposure } \\
\hline Population & FARM 3 & FARM 2 & FARM 1 \\
\hline FARM 2 & $\mathbf{2 . 8 0 E - 0 6}$ & \multicolumn{3}{c}{-} \\
FARM 1 & $\mathbf{2 . 3 0 E - 0 5}$ & 0.2720 & - \\
LAB & $\mathbf{0 . 0 1 9 0}$ & $\mathbf{1 . 0 0 E - 0 7}$ & $\mathbf{1 . 7 0 E - 0 8}$
\end{tabular}

\begin{tabular}{l|rrr} 
Duration & \multicolumn{3}{|c}{ 3 hours exposure } \\
\hline Population & FARM 3 & FARM 2 & \multicolumn{1}{l}{ FARM 1 } \\
\hline FARM 2 & 1.70E-08 & \multicolumn{3}{|c}{-} \\
FARM 1 & $\mathbf{3 . 4 0 E - 1 0}$ & 0.6024 & - \\
LAB & $\mathbf{0 . 0 0 0 2}$ & $\mathbf{5 . 3 0 E - 1 4}$ & $\mathbf{1 . 5 0 E - 1 4}$
\end{tabular}

\begin{tabular}{l|rrr} 
Duration & \multicolumn{3}{|c}{ 4 hours exposure } \\
\hline Population & FARM 3 & FARM 2 & FARM 1 \\
\hline FARM 2 & 0.0591 & - & - \\
FARM 1 & $\mathbf{5 . 0 0 E - 0 6}$ & 0.0591 & - \\
LAB & 0.0121 & 0.0002 & $\mathbf{1 . 1 0 E - 0 8}$
\end{tabular}

\begin{tabular}{l|lll} 
LAB & 0.0720 & 0.1430 & 0.2050
\end{tabular}

\begin{tabular}{l|rrr} 
Duration & \multicolumn{4}{|c}{ 1 hour exposure } \\
\hline Population & FARM 3 & FARM 2 & FARM 1 \\
\hline FARM 2 & 0.5049 & \multicolumn{3}{l}{-} \\
FARM 1 & 0.8946 & 0.5049 & - \\
LAB & $\mathbf{0 . 0 0 3 9}$ & $\mathbf{0 . 0 4 4 9}$ & $\mathbf{0 . 0 0 8 0}$
\end{tabular}

\begin{tabular}{l|rrl} 
Duration & \multicolumn{4}{|c}{ 2 hours exposure } \\
\hline Population & FARM 3 & FARM 2 & FARM 1 \\
\hline FARM 2 & 0.3069 & - & - \\
FARM 1 & $\mathbf{1 . 8 0 E - 0 7}$ & $\mathbf{0 . 0 0 4 2}$ & - \\
LAB & $<\mathbf{2 . 0 0 E - 1 6}$ & $\mathbf{2 . 2 0 E - 1 1}$ & $\mathbf{1 . 6 0 E - 1 0}$
\end{tabular}

\begin{tabular}{l|rrl} 
Duration & \multicolumn{3}{|c}{ 3 hours exposure } \\
\hline Population & FARM 3 & FARM 2 & FARM 1 \\
\hline FARM 2 & 0.4633 & - & - \\
FARM 1 & $\mathbf{0 . 0 0 1 9}$ & $\mathbf{0 . 0 0 8 0}$ & - \\
LAB & $\mathbf{2 . 0 0 E - 1 3}$ & $<\mathbf{2 . 0 0 E - 1 6}$ & $<\mathbf{2 . 0 0 E - 1 6}$
\end{tabular}

\begin{tabular}{l|rrl} 
Duration & \multicolumn{3}{|c}{ 4 hours exposure } \\
\hline Population & FARM 3 & FARM 2 & FARM 1 \\
\hline FARM 2 & 0.4142 & - & - \\
FARM 1 & $\mathbf{0 . 0 0 0 2}$ & $\mathbf{0 . 0 1 3 7}$ & - \\
LAB & $<\mathbf{2 . 0 0 E - 1 6}$ & $<\mathbf{2 . 0 0 E - 1 6}$ & $<\mathbf{2 . 0 0 E - 1 6}$
\end{tabular}

570 Appendix table 2: Detailed statistical results of experiment 2 (corresponding to results presented in

571 Figure 3 in the main text of the article). Overall ANOVA tests (type II) to the left, Sidak adjusted post

572 hoc test to the right. All data made using 95\% confidence level, significant P-values are presented in 573 bold.

\begin{tabular}{l|rrr}
\multicolumn{1}{c|}{ FARM1 } & \multicolumn{1}{|c}{ Chisq } & Df & \multicolumn{1}{c}{ P-value } \\
\hline Daily heat spikes & 0.6414 & 1 & 0.4232 \\
Cyfluthrin treatment & 16.6845 & 1 & $4.41 \mathrm{E}-05$ \\
Daily heat spikes \& Cyfluthrin & 1.1667 & 1 & 0.2801
\end{tabular}

\begin{tabular}{l|ccc}
\hline \multicolumn{1}{c|}{ FARM1 } & LCL & UCL & Group \\
\hline Daily heat spikes \& Cyfluthrin & 0.931 & 0.973 & a \\
Cyfluthrin treatment & 0.947 & 0.983 & ab \\
Control & 0.968 & 0.994 & b \\
Daily heat spikes & 0.973 & 0.996 & b
\end{tabular}

\begin{tabular}{l|rrr}
\hline \multicolumn{1}{c|}{ FARM2 } & \multicolumn{1}{|c}{ Chisq } & Df & P-value \\
\hline Daily heat spikes & 13.7 & 1 & $\mathbf{0 . 0 0 0 2 1 4}$ \\
Cyfluthrin treatment & 973.44 & 1 & $\mathbf{2 . 2 0 E}-16$ \\
Daily heat spikes \& Cyfluthrin & 0.08 & 1 & 0.775383
\end{tabular}

\begin{tabular}{l|ccc}
\hline \multicolumn{1}{c|}{ FARM2 } & LCL & UCL & Group \\
\hline Daily heat spikes \& Cyfluthrin & 0.484 & 0.567 & $\mathrm{a}$ \\
Cyfluthrin treatment & 0.569 & 0.651 & $\mathrm{~b}$ \\
Control & 0.981 & 0.999 & $\mathrm{c}$ \\
Daily heat spikes & 0 & 1 & $\mathrm{abc}$
\end{tabular}




\begin{tabular}{l|rrr}
\hline \multicolumn{1}{c|}{ FARM3 } & \multicolumn{1}{c}{ Chisq } & Df & P-value \\
\hline Daily heat spikes & 1.52 & 1 & 0.218 \\
Cyfluthrin treatment & 603.76 & 1 & $\mathbf{2 . 0 0 E}-16$ \\
Daily heat spikes \& Cyfluthrin & 0.02 & 1 & 0.8857
\end{tabular}

\begin{tabular}{l|ccc}
\hline \multicolumn{1}{c|}{ FARM3 } & LCL & UCL & Group \\
\hline Daily heat spikes \& Cyfluthrin & 0.329 & 0.469 & $\mathrm{a}$ \\
Cyfluthrin treatment & 0.377 & 0.519 & $\mathrm{a}$ \\
Control & 0.961 & 1 & $\mathrm{~b}$ \\
Daily heat spikes & 0.961 & 1 & $\mathrm{~b}$
\end{tabular}

\begin{tabular}{l|rrc}
\hline \multicolumn{1}{c|}{ LAB } & \multicolumn{1}{|c}{ Chisq } & Df & P-value \\
\hline Daily heat spikes & 9.53 & 1 & $\mathbf{0 . 0 0 2 0 1 8}$ \\
Cyfluthrin treatment & 631.06 & 1 & $\mathbf{2 . 2 0 E}-16$ \\
Daily heat spikes \& Cyfluthrin & 0.27 & 1 & 0.604759
\end{tabular}

\begin{tabular}{l|ccc}
\hline \multicolumn{1}{c|}{ LAB } & LCL & UCL & Group \\
\hline Daily heat spikes \& Cyfluthrin & 0.084 & 0.193 & a \\
Cyfluthrin treatment & 0.177 & 0.315 & b \\
Control & 0.929 & 0.999 & c \\
Daily heat spikes & 0.929 & 0.999 & c
\end{tabular}

582 Appendix table 3: Detailed statistical result of experiment 3 (corresponding to results presented in

583 Figure 4 in the main text of the article). Pairwise comparisons using Log-Rank test were performed

584 using the Survdiff function in R. Significant $p$ values are presented in bold.

Extreme heat $\left(42.5^{\circ} \mathrm{C}\right)$ tolerance data

\begin{tabular}{|c|c|c|c|}
\hline \multirow{2}{*}{$\begin{array}{l}\text { Insecticide conc. } \\
\text { mg cyfluthrin/ m2 }\end{array}$} & \multicolumn{2}{|c|}{ Pre-treatment peaks: } & \multirow{2}{*}{$\frac{\text { non }}{10}$} \\
\hline & 0 & 5 & \\
\hline 5 & $1.60 \mathrm{E}-06$ & & - \\
\hline 10 & $<2.00 \mathrm{E}-16$ & $3.40 \mathrm{E}-09$ & - \\
\hline 20 & $<2.00 \mathrm{E}-16$ & $<2.00 \mathrm{E}-16$ & $9.20 \mathrm{E}-14$ \\
\hline
\end{tabular}

\begin{tabular}{|c|c|c|c|}
\hline \multirow{2}{*}{$\begin{array}{l}\text { Insecticide conc. } \\
\text { mg cyfluthrin/ m2 }\end{array}$} & \multicolumn{2}{|c|}{ Pre-treatment peaks: } & \multirow{2}{*}{$\frac{32{ }^{\circ} \mathrm{C}}{10}$} \\
\hline & 0 & 5 & \\
\hline 5 & $2.2 \mathrm{E}-06$ & - & - \\
\hline 10 & $2.0 \mathrm{E}-14$ & $9.4 \mathrm{E}-09$ & - \\
\hline
\end{tabular}

Extreme cold $\left(-6^{\circ} \mathrm{C}\right)$ tolerance data

\begin{tabular}{r|ccc} 
Insecticide conc. & Pre-treatment peaks: & non \\
\cline { 2 - 4 } mg cyfluthrin/ m2 & 0 & 5 & 10 \\
\hline 5 & 0.4598 & - & - \\
10 & 0.0627 & 0.1072 & - \\
20 & $\mathbf{0 . 0 0 6 4}$ & $\mathbf{0 . 0 3 4 1}$ & 0.7462
\end{tabular}

\begin{tabular}{|c|c|c|c|}
\hline \multirow{2}{*}{$\begin{array}{l}\text { Insecticide conc. } \\
\text { mg cyfluthrin/ m2 }\end{array}$} & \multicolumn{2}{|c|}{ Pre-treatment peaks: } & \multirow{2}{*}{$\frac{32{ }^{\circ} \mathrm{C}}{10}$} \\
\hline & 0 & 5 & \\
\hline 5 & $1.0 \mathrm{E}-05$ & - & - \\
\hline 10 & 3.6E-07 & 0.25036 & - \\
\hline
\end{tabular}




$$
20 \mid<2.0 \mathrm{E}-16<2.0 \mathrm{E}-16 \quad 5.9 \mathrm{E}-07
$$

\begin{tabular}{|c|c|c|c|}
\hline \multirow{2}{*}{$\begin{array}{l}\text { Insecticide conc. } \\
\text { mg cyfluthrin/ m2 }\end{array}$} & \multicolumn{2}{|c|}{ Pre-treatment peaks: } & $38^{\circ} \mathrm{C}$ \\
\hline & 0 & 5 & 10 \\
\hline 5 & 0.17 & - & - \\
\hline 10 & 2.7E-05 & $1.3 \mathrm{E}-05$ & - \\
\hline 20 & $1.4 \mathrm{E}-14$ & $1.9 \mathrm{E}-15$ & 7.7E-05 \\
\hline
\end{tabular}

\begin{tabular}{l|l|}
20 & $5.2 \mathrm{E}-16 \quad 1.2 \mathrm{E}-05$
\end{tabular}

0.00038

\begin{tabular}{|c|c|c|c|}
\hline \multirow{2}{*}{$\begin{array}{l}\text { Insecticide conc. } \\
\text { mg cyfluthrin/ m2 }\end{array}$} & \multicolumn{2}{|c|}{ Pre-treatment peaks: } & \multirow{2}{*}{$\begin{array}{r}38^{\circ} \mathrm{C} \\
10 \\
\end{array}$} \\
\hline & 0 & 5 & \\
\hline 5 & 0.25 & - & - \\
\hline 10 & 0.7 & 0.65 & - \\
\hline 20 & $5.0 \mathrm{E}-07$ & $8.3 \mathrm{E}-08$ & $1.3 \mathrm{E}-07$ \\
\hline
\end{tabular}

585

Appendix table 4: Bold numbers represent $\mathrm{p}$ values showing significant differences between graphs, bold and italicized $\mathrm{p}$ values showing significantly slower recovery in insects having experienced daily heat spikes in pre-treatment.

\begin{tabular}{|c|c|c|c|c|}
\hline Pre-treatment & \multicolumn{2}{|c|}{ constant VS $32{ }^{\circ} \mathrm{C}$ peaks } & \multicolumn{2}{|c|}{ constant VS $38^{\circ} \mathrm{C} \mathrm{p} 58 \mathrm{~g}$} \\
\hline Extreme temp. & $42.5^{\circ} \mathrm{C}$ & $-6^{\circ} \mathrm{C}$ & $42.5^{\circ} \mathrm{C}$ & $-6^{\circ} \mathrm{C}$ \\
\hline Cyfluthrin conc. 0 & 0.036 & 0.092 & 0.045 & 0.29 \\
\hline Cyfluthrin conc. 5 & 0.02 & 0.07 & $<0.0001$ & 0.0016 \\
\hline Cyfluthrin conc. 10 & 0.068 & 0.62 & $<0.0001$ & 0.00041 \\
\hline Cyfluthrin conc. 20 & $<0.0001$ & $<0.0001$ & $<0.0001$ & 0.4 \\
\hline
\end{tabular}

\section{References}

Abbes, Khaled et al. 2015. "Combined Non-Target Effects of Insecticide and High Temperature on the Parasitoid Bracon Nigricans." PLoS ONE 10(9): e0138411.

Addo-Bediako, Abraham, Steven L Chown, and Kevin J Gaston. 2000. "Thermal Tolerance , Climatic Variability and Latitude." Proceedings of the Royal Society of London B 267(1445): 739-45.

ANSES. 2020. "Bulletin Mensuel Des Autorisations de Mise Sur Le Marché (AMM) Des Produits Phytopharmaceutiques et Adjuvants." Agence Nationale de Sécurité Sanitaire 2020(10).

Arambourou, Hélène, and Robby Stoks. 2015. "Combined Effects of Larval Exposure to a Heat Wave and Chlorpyrifos in Northern and Southern Populations of the Damselfly Ischnura Elegans." Chemosphere 128: 148-54.

Arias, María Belén, María Josefina Poupin, and Marco A. Lardies. 2011. "Plasticity of Life-Cycle, Physiological Thermal Traits and Hsp70 Gene Expression in an Insect along the Ontogeny: 
Effect of Temperature Variability." Journal of Thermal Biology 36(6): 355-62.

Arthur, Frank H. 1999. "Effect of Temperature on Residual Toxicity of Cyfluthrin Wettable Powder." Journal of Economic Entomology 92(3): 695-99.

Aviles, Amandine et al. 2019. "Effects of DEHP on Post-Embryonic Development, Nuclear Receptor Expression, Metabolite and Ecdysteroid Concentrations of the Moth Spodoptera Littoralis." Chemosphere 215: 725-38.

Op de Beeck, Lin, Julie Verheyen, and Robby Stoks. 2017. "Integrating Both Interaction Pathways between Warming and Pesticide Exposure on Upper Thermal Tolerance in Highand Low-Latitude Populations of an Aquatic Insect." Environmental Pollution 224: 714-21.

- - . 2018. "Strong Differences between Two Congeneric Species in Sensitivity to Pesticides in a Warming World." Science of the Total Environment 618: 60-69.

Benjamini, Yoav, and Yosef Hochberg. 1995. "Controlling the False Discovery Rate: A Practical and Powerful Approach to Multiple Testing." Journal of the Royal Statistical Society: Series B (Methodological) 57(1): 289-300.

Bindesbøl, Anne-Mette, Mark Bayley, Christian Damgaard, and Martin Holmstrup. 2009. "Impacts of Heavy Metals, Polyaromatic Hydrocarbons, and Pesticides on Freeze Tolerance of the Earthworm Dendrobaena Octaedra." Environmental Toxicology and Chemistry 28(11): 2341-47.

Bjørge, Julie Dahl et al. 2018. "Role of Temperature on Growth and Metabolic Rate in the Tenebrionid Beetles Alphitobius Diaperinus and Tenebrio Molitor." Journal of Insect Physiology 107: 89-96.

Böttger, R., J. Schaller, and S. Mohr. 2012. "Closer to Reality - the Influence of Toxicity Test Modifications on the Sensitivity of Gammarus Roeseli to the Insecticide Imidacloprid." Ecotoxicology and Environmental Safety 81: 49-54.

Bozinovic, Francisco et al. 2011. "The Mean and Variance of Environmental Temperature Interact to Determine Physiological Tolerance and Fitness." Physiological and Biochemical Zoology 84(6): 543-52.

Bozinovic, Francisco, and Hans Otto Pörtner. 2015. "Physiological Ecology Meets Climate Change." Ecology and Evolution 5(5): 1025-30.

Buchwalter, David B., Jeffrey J. Jenkins, and Lawrence R. Curtis. 2003. "Temperature Influences on Water Permeability and Chlorpyrifos Uptake in Aquatic Insects with Differing Respiratory Strategies." Environmental Toxicology and Chemistry 22(11): 2806-12.

Buckley, Lauren B. et al. 2010. “Can Mechanism Inform Species' Distribution Models?" Ecology Letters 13(8): 1041-54.

Cairns, John, Alan G. Heath, and Bruce C. Parker. 1975. "The Effects of Temperature upon the Toxicity of Chemicals to Aquatic Organisms." Hydrobiologia 47(1): 135-71. 
Calow, P. 1991. "Physiological Costs of Combating Chemical Toxicants: Ecological Implications." Comparative Biochemistry and Physiology. Part C, Comparative 100(1-2): 3-6.

Camp, A. A., and D. B. Buchwalter. 2016. "Can't Take the Heat: Temperature-Enhanced Toxicity in the Mayfly Isonychia Bicolor Exposed to the Neonicotinoid Insecticide Imidacloprid." Aquatic Toxicology 178: 49-57.

Cavieres, Grisel et al. 2019. "Transgenerational and within - Generation Plasticity Shape Thermal Performance Curves." Ecology and Evolution: 1-11.

Chen, Xi, and Jonathon H Stillman. 2012. "Multigenerational Analysis of Temperature and Salinity Variability Affects on Metabolic Rate, Generation Time, and Acute Thermal and Salinity Tolerance in Daphnia Pulex." Journal of Thermal Biology 37: 185-94.

Chernaki-Leffer, Andreia Mauruto, Daniel Ricardo Sosa-Gómez, Lúcia M. Almeida, and Ivani de Oliveira Negrão Lopes. 2011. "Susceptibility of Alphitobius Diaperinus (Panzer) (Coleoptera, Tenebrionidae) to Cypermethrin, Dichlorvos and Triflumuron in Southern Brazil." Revista Brasileira de Entomologia 55(1): 125-28.

Chidawanyika, Frank, and John S Terblanche. 2010. "Rapid Thermal Responses and Thermal Tolerance in Adult Codling Moth Cydia Pomonella (Lepidoptera: Tortricidae)." Journal of Insect Physiology 57: 108-17.

Chown, Steven L. et al. 2010. "Adapting to Climate Change: A Perspective from Evolutionary Physiology." Climate Research 43(1-2): 3-15.

Colinet, Hervé, Brent J. Sinclair, Philippe Vernon, and David Renault. 2015. "Insects in Fluctuating Thermal Environments." Annual Review of Entomology 60(1): 123-40.

Delnat, Vienna et al. 2019. "Temperature Variation Magnifies Chlorpyrifos Toxicity Differently between Larval and Adult Mosquitoes." Science of the Total Environment 690: 1237-44.

Delnat, Vienna, Lizanne Janssens, and Robby Stoks. 2019. "Whether Warming Magnifies the Toxicity of a Pesticide Is Strongly Dependent on the Concentration and the Null Model." Aquatic Toxicology 211: 38-45.

Desvignes-Labarthe, A. 2018. Master thesis dissertation, University Pierre \& Marie Curie, Paris, France "Détection et Quantification de La Résistance Aux Insecticides Chez Alphitobius Diaperinus (Tenebrionidae), Un Insecte Invasif Des Agro-Écosystèmes."

Dewer, Youssef et al. 2016. "Behavioral and Metabolic Effects of Sublethal Doses of Two Insecticides, Chlorpyrifos and Methomyl, in the Egyptian Cotton Leafworm, Spodoptera Littoralis (Boisduval) (Lepidoptera: Noctuidae)." Environmental Science and Pollution Research 23(4): 3086-96.

Dinh, Khuong V., Lizanne Janssens, and Robby Stoks. 2016. "Exposure to a Heat Wave under Food Limitation Makes an Agricultural Insecticide Lethal: A Mechanistic Laboratory Experiment." Global Change Biology 22(10): 3361-72.

Donald, James O. 2010. Ross Broiler Report Environmental Management in the Broiler House. 
Engell Dahl, Julie et al. 2019. "Thermal Tolerance Patterns of a Carabid Beetle Sampled along Invasion and Altitudinal Gradients at a Sub-Antarctic Island." Journal of Thermal Biology 86: 102447.

Fox, John, and Sanford Weisberg. 2019. An R Companion to Applied Regression. Third edit. Thousand Oaks CA.

Geden, Christopher J., and Jerome A. Hogsette. 1994. "Research and Extension Needs for Integrated Pest Management for Arthropods of Veterinary Importance." Proceeding of a workshop in Lincoln, Nebraska. (October): 1-328.

Graves, Spencer, Hans-Peter Piepho, and Luciano Selzer. 2019. "MultcompView: Visualizations of Paired Comparisons. R Package Version 0.1-8." https://cran.rproject.org/package=multcompView.

Guillebeau, L. P., J. N. All, and A. M. Javid. 1989. "Influence of Weather on Efficacy of Pyrethroid Insecticides for Boll Weevil (Coleoptera: Curculionidae) and Bollworm (Lepidoptera: Noctuidae) in Cotton." Journal of Economic Entomology 82(1): 291-96.

Hamm, Ronda L et al. 2006. "Resistance to Cyfluthrin and Tetrachlorvinphos in the Lesser Mealworm, Alphitobius Diaperinus, Collected from the Eastern United States." Pest Management Science 62: 673-77.

Hansen, James, Makiko Sato, and Reto Ruedy. 2012. "Perception of Climate Change." Proceedings of the National Academy of Sciences of the United States of America 109(37).

Harwood, Amanda D., Jing You, and Michael J. Lydy. 2009. "Temperature as a Toxicity Identification Evaluation Tool for Pyrethroid Insecticides: Toxicokinetic Confirmation." Environmental Toxicology and Chemistry 28(5): 1051-58.

Hawkins, Nichola J., Chris Bass, Andrea Dixon, and Paul Neve. 2018. "The Evolutionary Origins of Pesticide Resistance." Biological Reviews 94(1): 135-55.

Hazell, Steaphan P. et al. 2008. "A Method for the Rapid Measurement of Thermal Tolerance Traits in Studies of Small Insects." Physiological Entomology 33(4): 389-94.

Heath, Susan, Wayne A. Bennett, James Kennedy, and Thomas L. Beitinger. 1994. "Heat and Cold Tolerance of the Fathead Minnow, Pimephales Promelas, Exposed to the Synthetic Pyrethroid Cyfluthrin." Canadian Journal of Fisheries and Aquatic Sciences 51(2): 437-40.

Hirose, Masafumi, and Kenji Nakamura. 2005. "Spatial and Diurnal Variation of Precipitation Systems over Asia Observed by the TRMM Precipitation Radar." Journal of Geophysical Research D: Atmospheres 110(5): 1-14.

Holmstrup, Martin et al. 2010. "Interactions between Effects of Environmental Chemicals and Natural Stressors: A Review." Science of the Total Environment 408(18): 3746-62.

Hooper, Michael J. et al. 2013. "Interactions between Chemical and Climate Stressors: A Role for Mechanistic Toxicology in Assessing Climate Change Risks." Environmental Toxicology and Chemistry 32(1): 32-48. 
Huey, Raymond B, and R D Stevenson. 1979. "Intergrating Thermal Physiology and Ecology of Ecotherms: A Discussion of Approaches." American Zoologist 19(1): 357-66.

IPCC. 2014. Climate Change 2014: Synthesis Report. Contribution of Working Groups I, II and III to the Fifth Assessment Report of the Intergovernmental Panel on Climate Change Summary for Policymakers.

Johnson, Félicia, Adolphe Gueu Gbon, and Jean Pierre Boga. 2018. "Insectes Des Bâtiments d'élevages Avicoles Des Fermes de Bingerville, Côte d'Ivoire : Alphitobius Diaperinus (Panzer, 1797) (Coleoptera: Tenebrionidae)." European Scientific Journal, ESJ 14(27): 21528.

Käfer, Helmut et al. 2020. "Temperature Tolerance and Thermal Environment of European Seed Bugs." Insects 11(3).

Kassambara, Alboukadel, and Marcin Kosinski. 2018. "Survminer: Drawing Survival Curves Using 'Ggplot2'. R Package Version 0.4.3.” https://cran.r-project.org/package=survminer.

Katz, Richard W, and Barbara G Brown. 1992. "Extreme Events in a Changing Climate: Variability Is More Important than Averages." Climatic Change 21: 289-302.

Kaunisto, Sirpa, Laura V Ferguson, and Brent J Sinclair. 2016. "Can We Predict the Effects of Multiple Stressors on Insects in a Changing Climate?" Current Opinion in Insect Science 17: 55-61.

Khan, Hafiz Azhar Ali, and Waseem Akram. 2014. "The Effect of Temperature on the Toxicity of Insecticides against Musca Domestica L.: Implications for the Effective Management of Diarrhea." PloS one 9(4): e95636.

Kingsolver, Joel G., Sarah E. Diamond, and Lauren B. Buckley. 2013. "Heat Stress and the Fitness Consequences of Climate Change for Terrestrial Ectotherms." Functional Ecology 27(6): 1415-23.

Kingsolver, Joel G, Heidi J Maclean, Silvan B Goddin, and Kate E Augustine. 2016. "Plasticity of Upper Thermal Limits to Acute and Chronic Temperature Variation in Manduca Sexta Larvae." Journal of Experimental Biology 219: 1290-94.

Köhler, Heinz R., and Rita Triebskorn. 2013. "Wildlife Ecotoxicology of Pesticides: Can We Track Effects to the Population Level and Beyond?" Science 341(6147): 759-65.

Lachenicht, M W et al. 2010. "Effects of Acclimation Temperature on Thermal Tolerance, Locomotion Performance and Respiratory Metabolism in Acheta Domesticus L. (Orthoptera: Gryllidae)." Journal of Insect Physiology 56: 822-30.

Lalouette, Lisa et al. 2016. "Unexpected Effects of Sublethal Doses of Insecticide on the Peripheral Olfactory Response and Sexual Behavior in a Pest Insect." Environmental Science and Pollution Research 23(4): 3073-85.

Lambkin, Trevor A., and Steven J. Rice. 2009. "Baseline Responses of Alphitobius Diaperinus (Coleoptera: Tenebrionidae) to Cyfluthrin and Detection of Strong Resistance in Field 
Populations in Eastern Australia." Journal of Economic Entomology 99(3): 908-13.

Laskowski, Ryszard et al. 2010. "Interactions between Toxic Chemicals and Natural Environmental Factors - A Meta-Analysis and Case Studies." Science of The Total Environment 408(18): 3763-74.

Lenth, Russell V. 2020. “Emmeans: Estimated Marginal Means, Aka Least-Squares Means. R Package Version 1.5.3." https://cran.r-project.org/package=emmeans.

Lushchak, Volodymyr I et al. 2018. "Pesticide Toxicity: A Mechanistic Approach." EXCLI Journal 17: 1101-36.

Lydy, M. J., J. B. Belden, and M. A. Ternes. 1999. "Effects of Temperature on the Toxicity of MParathion, Chlorpyrifos, and Pentachlorobenzene to Chironomus Tentans." Archives of Environmental Contamination and Toxicology 37(4): 542-47.

Ma, Gang, Ary A. Hoffmann, and Chun Sen Ma. 2015. "Daily Temperature Extremes Play an Important Role in Predicting Thermal Effects." Journal of Experimental Biology 218(14): 2289-96.

Maino, James L, Paul A Umina, and Ary A Hoffmann. 2018. "Climate Contributes to the Evolution of Pesticide Resistance." Global Ecology and Biogeography 27: 223-32.

Mann, Michael E, Raymond S Bradley, and Malcolm K Hughes. 1998. "Global-Scale Temperature Patterns and Climate Forcing over the Past Six Centuries." Nature 392: 779-87.

Matzrafi, Maor. 2019. "Climate Change Exacerbates Pest Damage through Reduced Pesticide Efficacy." Pest Management Science 75(1): 9-13.

Meng, Shandong, Vienna Delnat, and Robby Stoks. 2020. "The Exposure Order Strongly Modifies How a Heat Spike Increases Pesticide Toxicity." Environmental Science and Technology 54(18): 11476-84.

Miller, Merrill C., Harvey W. Mohrenweiser, and Douglas A. Bell. 2001. "Genetic Variability in Susceptibility and Response to Toxicants." Toxicology Letters 120(1-3): 269-80.

Moe, S Jannicke et al. 2013. "Combined and Interactive Effects of Global Climate Change and Toxicants on Populations and Communities." Environmental Toxicology and Chemistry 32(1): 49-61.

Nakagawa, Lia Emi et al. 2017. "Pyrethroid Concentrations and Persistence Following Indoor Application." Environmental Toxicology and Chemistry 36(11): 2895-98.

Neven, L. G. 2000. "Physiological Responses of Insects to Heat." Postharvest Biology and Technology 21(1): 103-11.

Noyes, Pamela D. et al. 2009. "The Toxicology of Climate Change: Environmental Contaminants in a Warming World." Environment International.

Noyes, Pamela D., and Sean C. Lema. 2015. "Forecasting the Impacts of Chemical Pollution and Climate Change Interactions on the Health of Wildlife." Current Zoology 61(4): 669-89. 
Oliver, Shüné V., and Basil D. Brooke. 2017. "The Effect of Elevated Temperatures on the Life History and Insecticide Resistance Phenotype of the Major Malaria Vector Anopheles Arabiensis (Diptera: Culicidae)." Malaria Journal 16(73).

Orr, James A. et al. 2020. "Towards a Unified Study of Multiple Stressors: Divisions and Common Goals across Research Disciplines." Proceedings of the Royal Society B: Biological Sciences 287(1926).

Overgaard, Johannes et al. 2007. "Metabolomic Profiling of Rapid Cold Hardening and Cold Shock in Drosophila Melanogaster." Journal of Insect Physiology 53: 1218-32.

Overgaard, Johannes, Ary A. Hoffmann, and Torsten N. Kristensen. 2011. "Assessing Population and Environmental Effects on Thermal Resistance in Drosophila Melanogaster Using Ecologically Relevant Assays." Journal of Thermal Biology 36: 409-16.

Patra, Ronald W., John C. Chapman, Richard P. Lim, and Peter C. Gehrke. 2007. "The Effects of Three Organic Chemicals on the Upper Thermal Tolerances of Four Freshwater Fishes." Environmental Toxicology and Chemistry 26(7): 1454-59.

Pu, Jian, Zinan Wang, and Henry Chung. 2020. "Climate Change and the Genetics of Insecticide Resistance." Pest Management Science 76(3): 846-52.

R Core Team. 2013. "R: A Language and Environment for Statistical Computing." http://www.rproject.org/.

Renault, David. 2011. "Long-Term after-Effects of Cold Exposure in Adult Alphitobius Diaperinus (Tenebrionidae): The Need to Link Survival Ability with Subsequent Reproductive Success." Ecological Entomology 36(1): 36-42.

Renault, David, and Hervé Colinet. 2021. Large Differences in the Susceptibility to Commercial Insecticides among Several Populations of the Lesser Mealworm (Alphitobius Diaperinus) Collected from Poultry Houses in France.

Rice, S. J., and T. A. Lambkin. 2009. "A New Culture Method for Lesser Mealworm, Alphitobius Diaperinus." Journal of Applied Entomology 133(1): 67-72.

Rueda, L. M., and R. C. Axtell. 1997. "Arthropods in Litter of Poultry (Broiler Chicken and Turkey) Houses." Journal of Agricultural Entomology 14(1): 81-91.

Salin, Christophe, Y. R. Delettre, and Philippe Vernon. 2003. "Controlling the Mealworm Alphitobius Diaperinus (Coleoptera: Tenebrionidae) in Broiler and Turkey Houses: Field Trials with a Combined Insecticide Treatment: Insect Growth Regulator and Pyrethroid." Journal of Economic Entomology 96(1): 126-30.

Salin, Christophe, and Philippe Vernon. 1997. Rapport scientifique Bayern AG, Université de Rennes-1 et UMR 6553 Efficiency Tests in Natural Conditions of Baycidal (Triflumuron) and Solfac (Cyfluthrine) against Coleoptera in Poultry Breeding Systems.

Satpute, N. S. et al. 2007. "Temperature-Dependent Variation in Toxicity of Insecticides against Earias Vitella (Lepidoptera: Noctuidae)." Journal of Economic Entomology 100(2): 357-60. 
Sinclair, Brent J. et al. 2016. "Can We Predict Ectotherm Responses to Climate Change Using Thermal Performance Curves and Body Temperatures?" Ecology Letters 19(11): 1372-85.

Sinclair, Brent J., Laura V. Ferguson, Golnaz Salehipour-Shirazi, and Heath A. Macmillan. 2013. "Cross-Tolerance and Cross-Talk in the Cold: Relating Low Temperatures to Desiccation and Immune Stress in Insects." Integrative and Comparative Biology 53(4): 545-56.

Sinclair, Brent J, Litza E Coello Alvarado, and Laura V Ferguson. 2015. "An Invitation to Measure Insect Cold Tolerance: Methods, Approaches, and Workflow." Journal of Thermal Biology 53: 180-97.

Soranno, Patricia A. et al. 2019. "Spatial and Temporal Variation of Ecosystem Properties at Macroscales." Ecology Letters 22(10): 1587-98.

Stillman, Jonathon H. 2019. "Heat Waves, the New Normal: Summertime Temperature Extremes Will Impact Animals, Ecosystems, and Human Communities." Physiology 34(2): 86-100.

Tang, Wangxin et al. 2017. "Pyrethroid Pesticide Residues in the Global Environment: An Overview." ECSN. https://doi.org/10.1016/j.chemosphere.2017.10.115.

Teets, Nicholas M., and David L. Denlinger. 2013. "Physiological Mechanisms of Seasonal and Rapid Cold-Hardening in Insects." Physiological Entomology 38(2): 105-16.

Tilman, David et al. 2002. "Agricultural Sustainability and Intensive Production Practices." Nature 418: 671-77.

Vasseur, David A et al. 2014. "Increased Temperature Variation Poses a Greater Risk to Species than Climate Warming." Proceedings of the royal society B 281: 20132612.

Verheyen, Julie, Vienna Delnat, and Robby Stoks. 2019. "Increased Daily Temperature Fluctuations Overrule the Ability of Gradual Thermal Evolution to Offset the Increased Pesticide Toxicity under Global Warming." Environmental Science and Technology 53(8): 4600-4608.

Verheyen, Julie, and Robby Stoks. 2019. "Current and Future Daily Temperature Fluctuations Make a Pesticide More Toxic: Contrasting Effects on Life History and Physiology." Environmental Pollution 248: 209-18.

Weldon, Christopher W., John S. Terblanche, and Steven L. Chown. 2011. "Time-Course for Attainment and Reversal of Acclimation to Constant Temperature in Two Ceratitis Species." Journal of Thermal Biology 36(8): 479-85. https://linkinghub.elsevier.com/retrieve/pii/S0306456511001136 (July 18, 2019).

Willming, Morgan M., Guangqiu Qin, and Jonathan D. Maul. 2013. "Effects of Environmentally Realistic Daily Temperature Variation on Pesticide Toxicity to Aquatic Invertebrates." Environmental Toxicology and Chemistry 32(12): 2738-45.

Zhu, Y. J., C. Sengonca, and B. Liu. 2006. "Toxicity of Biocide GCSC-BtA on Arthropod Pests under Different Temperature Conditions." Journal of Pest Science 79(2): 89-94. 
863 
Highlights:

- Thermal tolerance varied among populations of the lesser mealworm

- Detrimental effect of simultaneous exposure to stressors, but no interaction

- Pre-exposure to daily heat peaks decreased recovery time from heat shock

- Previous insecticide exposure reduced tolerance of extreme temperatures 


\section{Declaration of interests}

$\bigotimes$ The authors declare that they have no known competing financial interests or personal relationships that could have appeared to influence the work reported in this paper.

$\square$ The authors declare the following financial interests/personal relationships which may be considered as potential competing interests: 